\title{
Structural changes of CAST soot during a thermal-optical measurement protocol
}

\author{
Theresa Haller ${ }^{1}$, Christian Rentenberger ${ }^{1}$, Jannik C. Meyer ${ }^{1}$, Laura Felgitsch ${ }^{2}$, Hinrich Grothe ${ }^{2}$, and \\ Regina Hitzenberger ${ }^{1}$ \\ ${ }^{1}$ Faculty of Physics, University of Vienna, Vienna, 1090, Austria \\ ${ }^{2}$ Institute of Materials Chemistry, TU Wien, Vienna, 1060, Austria
}

Correspondence: Regina Hitzenberger (regina.hitzenberger@univie.ac.at)

Received: 8 January 2019 - Discussion started: 11 February 2019

Revised: 7 May 2019 - Accepted: 9 May 2019 - Published: 2 July 2019

\begin{abstract}
Thermal-optical measurement techniques are widely used to classify carbonaceous material. The results of different methods for total carbon are comparable but can vary by $>44 \%$ for elemental carbon. One major cause of variation is the formation of pyrolyzed carbon during the heating process which occurs mainly in samples with a high amount of brown carbon $(\mathrm{BrC})$. In this study the structural changes of two different CAST (combustion aerosol standard) aerosol samples caused by the heating procedure in a thermal-optical instrument were investigated with UV-VIS and Raman spectroscopy, the integrating-sphere technique (IS) and transmission electron microscopy. All analysis techniques showed significant structural changes for $\mathrm{BrC}$-rich samples at the highest temperature level $\left(870^{\circ} \mathrm{C}\right)$ in helium. The structure of the heated $\mathrm{BrC}$-rich sample resembles the structure of an unheated $\mathrm{BrC}$-poor sample. Heating the $\mathrm{BrC}$ rich sample to $870^{\circ} \mathrm{C}$ increases the graphitic domain size within the material from 1.6 to $2 \mathrm{~nm}$. Although the Raman spectra unambiguously show this increase in ordering only at the highest temperature step, UV-VIS and IS analyses show a continuous change in the optical properties also at lower temperatures. The sample with a negligible amount of $\mathrm{BrC}$, however, did not show any significant structural changes during the whole heating procedure.
\end{abstract}

\section{Introduction}

Carbonaceous material contributes a large amount to atmospheric aerosols from $20 \%$ of alpine $\mathrm{PM}_{2.5}$ up to $40 \%$ of urban $\mathrm{PM}_{2.5}$ (Pöschl, 2005) and up to $50 \%$ in $\mathrm{PM}_{10}$ (Yttri et al., 2007). Major sources include incomplete combustion of fossil and biogenic fuels, emission of primary particles by the biosphere, and gas-to-particle conversion of precursor gases emitted by the biosphere or anthropogenic activities (IPCC, 2013; Després et al., 2012; Zhu et al., 2018; McNeill, 2017). Carbon-containing aerosols influence the global radiation balance due to their optical properties and their capability to act as cloud condensation nuclei and ice-nucleating particles. In particular, black carbon (BC) has an important effect on radiative forcing as it has the strongest light absorption of all aerosol components (Bond and Bergstrom, 2006; IPCC, 2013). Carbonaceous material has also been found to cause various deleterious health effects (Highwood and Kinnersley, 2006; Anderson et al., 2012; Mesquita et al., 2017; EEA, 2017; Partanen et al., 2018; Rohr and McDonald, 2015).

Depending on its origin carbonaceous material ranges from agglomerations of primary spherical particles with a graphitic-like internal structure to non-ordered organic material. While primary carbonaceous particles produced under well-defined combustion conditions are rather homogeneous, real-atmosphere carbonaceous particles are internal mixtures of different carbonaceous and non-carbonaceous materials of various origins (e.g., Okada and Hitzenberger, 2001; Zhang et al., 2014; Ye et al., 2018; IPCC, 2013; Deboudt et al., 2010; Pratt and Prather, 2010; Bondy et al., 2018; Adachi et al., 2010; Adachi and Buseck, 2013; China et al., 2013; Cappa et al., 2012). As carbonaceous aerosol material plays such an important role and is so diverse, the correct determination of carbonaceous fractions in the aerosol is essential. However, this endeavor is not trivial because measurement 
techniques are influenced not only by the properties of the material itself, but also by the non-carbonaceous materials associated with the particles and their mixing state.

During the past decades, numerous methods were developed, and intercomparison studies of different methods applied to both laboratory-generated and ambient aerosol were performed, which showed similarities and discrepancies of the results of different methods depending on sources and aerosol constituents (see, e.g., the overviews given by Watson et al., 2005; Venkatachari et al., 2006; Müller et al., 2004).

Analysis techniques can be grouped broadly into optical techniques, which utilize light absorption and its wavelength dependence, and thermal techniques, which separate the material based on its thermal properties. Another distinction can be made between filter-based techniques and techniques that analyze airborne particles in situ, such as photoacoustic spectrometry (e.g., Arnott et al., 1999; Moosmüller et al., 1998) and the SP2 instrument (e.g., Stephens et al., 2003; Schwartz et al., 2006). Usually, the term black carbon (BC) is used for the carbonaceous fraction with high light absorption in the whole visible wavelength range, and brown carbon $(\mathrm{BrC})$ is used for the carbonaceous fraction with a pronounced wavelength-dependent absorption with high absorption in the blue and weak absorption in the red part of the spectrum (Petzold et al., 2013). Thermal techniques separate carbonaceous material into organic carbon (OC, thermally unstable) and elemental carbon (EC, thermally refractory). The latter oxidizes in air at temperatures above $600^{\circ} \mathrm{C}(\mathrm{An}$ dreae and Gelencsér, 2006) and does not evaporate in the absence of oxygen below fairly high temperatures (the definitions range from $550^{\circ} \mathrm{C}$, Bond and Bergstrom, 2006; to $700^{\circ} \mathrm{C}$, Chow et al., 2004). EC and BC are often loosely used as synonymous, as both are strongly light absorbing, although the terms are not the same since EC is defined by thermal and $\mathrm{BC}$ by optical properties of the material (Buseck et al., 2014; Petzold et al., 2013). The comparability of BC and/or EC values measured with different techniques depends on the composition of the aerosol and the measurement method (Cheng et al., 2012; Cavalli et al., 2010). Optically determined $\mathrm{BrC}$ is a subfraction of thermally determined OC and originates mainly from combustion of biomass or biofuels (Mayol-Bracero, 2002; Hoffer et al., 2006; Schmidl et al., 2008; Park et al., 2018; Fan et al., 2016; Park and Yu, 2016; Sun et al., 2017). The thermal and optical behavior of carbonaceous material is caused by its internal structure (i.e., chemical composition, ordering and bonding types). As outlined by Pöschl (2005) there is no sharp boundary between the thermally unstable $\mathrm{OC}$ and $\mathrm{EC}$ but a continuous transition from organic carbon to elemental carbon in terms of structure as well as of thermal and optical properties: the higher the degree of graphitization, the higher the thermal stability and the broader the wavelength range of light absorption are.

In order to account for pyrolyzation of OC during the heating process used in the thermal techniques, thermal-optical techniques were developed. In these techniques the sample is heated stepwise first in an inert He atmosphere to a maximum temperature, which depends on the measurement protocol (see below), and then oxygen is added to the carrier gas and the sample is further heated. The amount of carbon leaving the filter at each temperature step is detected. The darkening of the sample due to pyrolysis is traced by monitoring a transmission/reflection laser signal. After the addition of oxygen both the originally present EC and the pyrolyzed carbon (PC) are oxidized during the successive heating steps. All carbon leaving the filter until the laser signal has reached its original value is assumed to originate from PC and is attributed to the $\mathrm{OC}$ fraction in the subsequent evaluation.

The crucial assumption for this laser correction is that either PC has the same molecular structure as the original EC or that PC burns off completely before EC is oxidized. None of these conditions is fulfilled, as was shown by Yu and Yang (2002), who found that in many cases the light absorption coefficient $(\sigma)$ of the two fractions is not the same at least at the wavelength used in their thermal-optical instrument $(680 \mathrm{~nm})$. Moreover, the value of $\sigma$ of PC is not constant even during a single thermal analysis. This uncertainty in accounting for PC leads to uncertainties in the OC/EC split, which is the subject of numerous instrument intercomparison studies (see, e.g., the overview given by Cavalli et al., 2010).

Different thermal-optical measurement protocols vary in height and duration of the individual temperature steps, particularly in the maximum temperature of the inert $(\mathrm{He})$ mode - maximum temperatures between $580^{\circ} \mathrm{C}$ (IMPROVE A, Chow et al., 2004) and $870^{\circ} \mathrm{C}$ (NIOSH870, Panteliadis et al., 2015; Birch and Cary, 1996). This leads to different charring behaviors of OC. As a consequence the OC/EC split varies with the temperature protocol, while the total carbon (TC, i.e., the sum of OC; EC; and, if present, carbonate carbon) values usually are quite comparable. Different thermal methods agree within $5 \%-15 \%$ in the amount of TC but vary up to $44 \%$ for EC (Reisinger et al., 2008; Cavalli et al., 2010; Yu and Yang, 2002; Cheng et al., 2012; Hitzenberger et al., 2006; Panteliadis et al., 2015).

The largest discrepancies between thermal-optical methods applied to atmospheric samples occur in the presence of appreciable amounts of $\mathrm{BrC}$ (e.g., Wonaschütz et al., 2009; Reisinger et al., 2008). Kim et al. (2015) compared OC and EC values obtained with two different thermal-optical protocols (NIOSH and EUSAAR) for laboratory-generated soot from propane combustion (produced by a miniCAST burner). For EC/TC ratios $>0.5$, the differences of EC/TC between both methods were below $15 \%$. For lower EC/TC ratios when significant amounts of $\mathrm{BrC}$ (measured with an optical method) were present, larger differences (30\%) are noticeable.

Besides the presence of $\mathrm{BrC}$, metal salts were also found to affect the OC/EC split in thermal-optical methods by enhancing the charring of $\mathrm{OC}$ and/or by reducing the oxidation temperature of EC (Wang et al., 2010; Bladt et al., 2014). 
The aim of the present study was to shed more light on the processes which lead to the discrepancies between measurement methods using different thermal-optical protocols. The formation of PC during thermal-optical measurements is not yet fully understood. The purpose was to investigate the structural changes of carbonaceous aerosol samples occurring during pyrolysis. In order to exclude the effects of other, non-carbonaceous material on the charring process, the structure of two different types of laboratory-generated soot - one with a high tendency to form PC and one with a negligible tendency to form PC - was analyzed in different stages of pyrolyzation in order to obtain more information about the internal structure of $\mathrm{PC}$ and its differences or analogies to the structure of EC. A thermal-optical EC-OC analyzer (Sunset Instruments Inc.; see description below) was used not only for the analysis of these soot samples but also as a means for sample preparation in order to obtain pyrolyzed samples from each heating step that had been exposed to the same atmospheres, heating rates and temperature plateaus as during the thermal-optical analysis. This approach permits an investigation of the structural changes of the material as they occur during the thermal-optical heating procedure. Although charring of organic material has also been observed in SP2 measurements (Sedlacek et al., 2018), the present study is focussed on the processes occurring in filter samples.

\section{Properties of soot}

\subsection{Structure of soot}

The general term soot is usually used for particulate products of incomplete combustion or pyrolysis of fossil fuels or organic materials (Andreae and Gelencsér, 2006; Pöschl, 2005; Bond and Bergstrom, 2006).

The structure of soot depends on the fuel and on the combustion conditions. Soot produced under oxygen-rich combustion conditions and high temperatures consists of agglomerated primary particles with sizes between 10 and $30 \mathrm{~nm}$ (Sadezky et al., 2005). The primary particles consist of onion-like turbostratically ordered graphitic layers. The graphitic domains typically include 3-4 graphene layers and have an extent of about $3 \mathrm{~nm}$ with interlayer distances of about $3.5 \AA$ (Sadezky et al., 2005), which is larger than the interlayer distance of an ideal graphitic lattice $(3.35 \AA$ ) because of the turbostratic arrangement. The atoms in graphitic-like material are bound with $\pi$ bonds, which form conjugated systems and hence long-range orbitals. As the optical gap is small $(\approx 0.5 \mathrm{eV}$ for disordered graphitic layers; Robertson and O'Reilly, 1987), light from a broad spectral range is absorbed (Bond and Bergstrom, 2006; Chhowalla et al., 1997).

In contrast to this highly ordered type of soot, the molecular structure of $\mathrm{BrC}$, which is formed under oxygen-poor and low-temperature combustion conditions, is similar to that of polycyclic hydrocarbons (PAH) or humic-like substances
(HULIS) (Graber and Rudich, 2006; Sun et al., 2007). Due to the smaller expansion of the molecular orbitals there is a larger optical gap between the filled valence band and the unfilled conduction band, which leads to a decreasing absorption efficiency towards the long-wave part of the visible spectrum (Bond, 2001; Kim et al., 2015; Andreae and Gelencsér, 2006).

\subsection{CAST soot}

For the present study, a combustion aerosol standard burner (type miniCAST) was used to produce differently structured soot by varying the combustion conditions. A detailed description of the miniCAST burner is given below. Different fuel-to-air ratios in the flame lead to different compositions and structures of the produced particles. According to Kim et al. (2015) and Mamakos et al. (2013) the particles obtained under oxygen-rich settings are comparable to diesel exhaust aerosols. They show a high EC fraction and form relatively large fractal agglomerates with mobility diameters between 70 and $130 \mathrm{~nm}$, which are composed of small $(25-30 \mathrm{~nm})$ spherical primary particles (Kim et al., 2015). Under oxygenpoor combustion conditions, spherical particles with sizes in the range 10-60 $\mathrm{nm}$ and a low EC fraction (Kim et al., 2015) are formed. While soot from biomass burning contains also ionic components such as $\mathrm{Na}^{+}, \mathrm{NH}_{4}^{+}, \mathrm{Ca}^{2+}, \mathrm{Mg}^{2+}, \mathrm{K}^{+}, \mathrm{Cl}^{-}$, $\mathrm{NO}_{3}^{-}$and $\mathrm{SO}_{4}^{2-}$ which could lead to catalysis effects in the thermal-optical analysis (Ichikawa and Naito, 2017; Wang et al., 2010), these compounds are negligible in soot produced by the CAST burner since only pure propane and air contribute to the combustion.

\subsection{Basics of Raman spectroscopy of soot}

Raman scattering has been used for the structural investigation of soot for several years (Rosen and Novakov, 1978; Sadezky et al., 2005; Ferrari and Robertson, 2000; Schmid et al., 2011; Knauer et al., 2009; Ivleva et al., 2007a, b). It is sensitive to different $\mathrm{C}-\mathrm{C}$ bonding types (e.g., graphitic structures) in a material (Sadezky et al., 2005) and depends on the ordering of $\mathrm{sp}^{2}$ sites (Ferrari and Robertson, 2000).

Ideal graphite shows a single peak at a Raman shift of $\approx 1580 \mathrm{~cm}^{-1}$ (G peak or graphitic peak), which is related to the ideal hexagonal environment in the extended graphene layers ( $E_{2 \mathrm{~g}}$ symmetry). For nonideal graphite, an additional peak at $\approx 1350 \mathrm{~cm}^{-1}$ (D peak or defect peak) appears, which is due to impurities and/or smaller graphene layers and the thus increased number of layer edges. Due to the missing neighbor atoms at these edges, the symmetry of the $\mathrm{C}-\mathrm{C}$ vibration is reduced to $A_{1 \mathrm{~g}}$. When the ordering in the material decreases - which is the case in soot - the two formerly sharp peaks broaden and overlap (see also Figs. 5 and 6) as a consequence of more than two overlapping Raman bands. To separate the contributions of the bands, different authors suggest different curve-fitting methods with up to 
five signals with either Gaussian or Lorentzian shape (Dippel et al., 1999; Jawhari et al., 1995; Sze et al., 2001; Cuesta et al., 1994). A comparison study performed by Sadezky et al. (2005) found that a five-curve fit with four Lorentzian and one Gaussian curves represents most of their spectra best. The curve shapes, band positions and related vibration modes are listed in Table 1.

The ratio of the intensities of the $\mathrm{D}$ and $\mathrm{G}$ peak $\left(I_{\mathrm{D}} / I_{\mathrm{G}}\right)$ can be linked to the crystallite size $\left(L_{\mathrm{a}}\right)$ within the investigated material (Ferrari and Robertson, 2000; Tuinstra and Koenig, 1970). Ferrari and Robertson (2000) propose an increase in $L_{\mathrm{a}}$ with increasing $I_{\mathrm{D}} / I_{\mathrm{G}}$ below $L_{\mathrm{a}} \approx 2 \mathrm{~nm}$. In this regime $I_{\mathrm{D}} / I_{\mathrm{G}}$ is proportional to the probability to find 6-fold aromatic rings in the cluster (Ferrari and Robertson, 2000). For larger crystallite sizes $I_{\mathrm{D}} / I_{\mathrm{G}}$ decreases with increase in $L_{\mathrm{a}}$ (Tuinstra and Koenig, 1970). $I_{\mathrm{D}} / I_{\mathrm{G}}$ shows a maximum at $L_{\mathrm{a}} \approx 2 \mathrm{~nm}$ but has a broad transition regime between the increasing and decreasing branch. Zickler et al. (2006) compare the $I_{\mathrm{D}} / I_{\mathrm{G}}$ ratio of Raman spectra of charcoal obtained from spruce wood with the crystallite sizes obtained from $\mathrm{X}$-ray diffraction and confirm the proposal of Ferrari and Robertson experimentally. Based on these findings, several authors (Commodo et al., 2016; Ess et al., 2016; Ivleva et al., $2007 \mathrm{a}, \mathrm{b}$ ) use increasing $I_{\mathrm{D}} / I_{\mathrm{G}}$ ratios as criteria to detect an increasing degree of ordering in soot.

\section{Experimental setup}

For the production of well-defined combustion soot, a combustion aerosol standard soot generator (type miniCAST 5201C Jing-CAST Technologies, http://www.sootgenerator. com, last access: 7 June 2019) was used. In this burner, soot is produced in a propane and air co-flow diffusion flame which was quenched with nitrogen directly after the combustion zone in order to prevent further combustion processes. The particle flow is subsequently diluted with air. The burning conditions were varied by setting different air-to-fuel ratios to produce differently structured soot.

Prior to this study, samples were obtained for a variety of air-to-fuel ratios and analyzed for $\mathrm{BC}$ and $\mathrm{BrC}$ with the integrating-sphere technique (IS; see below). Based on these experiments, two different combustion conditions were chosen here to produce two types of soot: one representing a BrC-rich sample ("brown") and the other a BrC-poor sample ("black") (Table 2). The samples have a completely different morphology, as is shown below in Figs. 9 and 10.

For sampling, quartz fiber filters (Pall Tissuquartz 2500 QAT-UP, $47 \mathrm{~mm}$ ) were used. The filters had been prebaked at $450^{\circ} \mathrm{C}$ for an hour and stored for at least $24 \mathrm{~h}$ in a water-vapor-saturated atmosphere before sampling to prevent adsorption of volatile organic substances during handling (Jankowski et al., 2008). The loaded filters were stored at $-22^{\circ} \mathrm{C}$ except during analysis and further sample prepara- tion (see below). The setup of the sampling system is shown in Fig. 1.

Part of the exhaust stream of the miniCAST was diverted and drawn through two parallel filters placed in identical holders. The total flow in this sampling line was controlled by a critical orifice $\left(12.5 \mathrm{~L} \mathrm{~min}^{-1}\right)$. The aerosol flow was diluted with $5 \mathrm{~L} \mathrm{~min}^{-1}$ air filtered with a HEPA (high-efficiency particulate air) filter, except for samples to be analyzed with UV-VIS spectroscopy, where the flow had to be diluted with $6 \mathrm{~L} \mathrm{~min}^{-1}$ air to prevent too-dark filter deposits. The dilution air was regulated with a needle valve and measured with a rotameter. For each of the following measurement techniques (UV-VIS, Raman spectroscopy, IS, TEM) a set of eight $1.5 \mathrm{~cm}^{2}$ filter punches was taken from the filters. For the preparation of the heated samples, the EC-OC analyzer (see description below) was programmed according to the NIOSH870 protocol and used as an oven. Each filter punch was inserted into the analyzer and underwent part of the NIOSH870 heating procedure, from the beginning to one of the first eight prescribed temperature levels (see Table 2). At that point the automated heating procedure was interrupted and the oven cooled down to below $75^{\circ} \mathrm{C}$ in Helium. Then the punches where removed from the instrument and transferred directly into Petri dishes. The dishes were closed with Parafilm strips and stored at $-22^{\circ} \mathrm{C}$ until the further measurements. This procedure was performed for four sets of filter punches to be analyzed with the different techniques.

\section{Analysis techniques}

\subsection{Thermal-optical measurements}

For the analysis of the filter samples and the heating of the samples a dual-optics EC-OC analyzer (Sunset Instruments Inc.) was used. In the first heating steps, the samples are heated in helium. In the second part of the analysis the samples are exposed to an oxidizing atmosphere consisting of $2 \%$ oxygen and $98 \%$ helium. Reflectance and transmittance signals of laser light $(635 \mathrm{~nm})$ are used to monitor the darkening of the sample caused by pyrolysis during heating in the inert atmosphere. In this study, the NIOSH870 protocol was used. Temperature steps and residence times are listed in Table 3.

The NIOSH870 protocol was chosen here to investigate the structural changes of soot during pyrolysis, because of the strong charring occurring in the He mode at the high temperatures. The EUSAAR2 protocol (Cavalli et al., 2010), which is now used widely in the EU (Brown et al., 2017), minimizes charring and is therefore less suitable for the investigation of PC.

\subsection{Integrating sphere (IS)}

$\mathrm{BC}$ and $\mathrm{BrC}$ (often taken together as light-absorbing carbon, LAC) of the original and the heated samples were analyzed 
Table 1. Band positions and line shapes for the five fitting curves of soot Raman spectra (Sadezky et al., 2005).

\begin{tabular}{llll}
\hline Band & Shape & $\begin{array}{c}\text { Position } \\
\left(\mathrm{cm}^{-1}\right)\end{array}$ & Vibration mode \\
\hline $\mathrm{D}_{\text {fit }}$ & Lorentzian & $\approx 1360$ & Disordered graphitic lattice $\left(A_{1 \mathrm{~g}}\right.$ symmetry $)$, graphene layer edges \\
$\mathrm{D} 2_{\text {fit }}$ & Lorentzian & $\approx 1620$ & Disordered graphitic lattice $\left(E_{2 \mathrm{~g}}\right.$ symmetry $)$, surface graphene layers \\
$\mathrm{D} 3_{\text {fit }}$ & Gaussian & $\approx 1500$ & Amorphous carbon \\
$\mathrm{D} 4_{\text {fit }}$ & Lorentzian & $\approx 1180$ & Disordered graphitic lattice $\left(A_{1 \mathrm{~g}}\right.$ symmetry $)$, polyenes, ionic impurities \\
$G_{\text {fit }}$ & Lorentzian & $\approx 1580$ & Ideal graphitic lattice $\left(E_{2 \mathrm{~g}}\right.$ symmetry $)$ \\
\hline
\end{tabular}

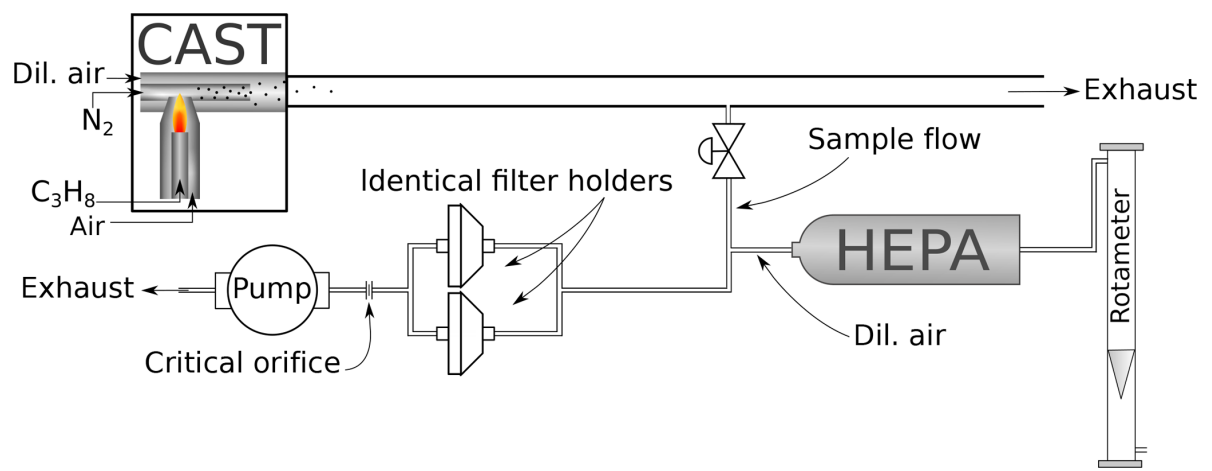

Figure 1. Setup of the sampling. Soot produced by the CAST generator is first diluted within the generator. The sample flow is drawn from the exit line of the CAST generator and further diluted with filtered air (dilution flow regulated with a needle valve and measured with a rotameter). Aerosol is sampled in parallel on filters placed in two identical filter holders. Total flow in the sampling line is regulated by a critical orifice $\left(12.5 \mathrm{Lmin}^{-1}\right)$.

Table 2. CAST burning conditions used for the black and the brown sample. The dilution air refers to the CAST internal dilution.

\begin{tabular}{lll}
\hline CAST burning conditions & Black & Brown \\
\hline Propane & $40 \mathrm{~mL} \mathrm{~min}^{-1}$ & $50 \mathrm{~mL} \mathrm{~min}^{-1}$ \\
Oxidation air & $1.04 \mathrm{Lmin}^{-1}$ & $0.9 \mathrm{~L} \mathrm{~min}^{-1}$ \\
Nitrogen & 0 & 0 \\
Dilution air & $20 \mathrm{Lmin}^{-1}$ & $10 \mathrm{Lmin}^{-1}$ \\
Quench gas $\left(\mathrm{N}_{2}\right)$ & $7 \mathrm{Lmin}^{-1}$ & $7 \mathrm{Lmin}^{-1}$ \\
C/O & 0.275 & 0.397 \\
\hline
\end{tabular}

with an extension of the original integrating-sphere technique (described, e.g., by Hitzenberger and Tohno, 2001). In this technique, a sample (e.g., a filter punch) is immersed in a liquid and introduced into the center of an integrating sphere illuminated with diffuse light. In our study, a $15.24 \mathrm{~cm}$ (6 in.) integrating sphere (Labsphere, Inc.) coated internally with a nearly ideally diffusely reflective $(>99 \%)$ material (Spectraflect $^{\mathrm{TM}}$ ) was used. Samples were immersed in a mixture of $10 \%$ isopropanol, $40 \% \mathrm{H}_{2} \mathrm{O}$ and $50 \%$ acetone in $\mathrm{PE}$ vials. Enhanced absorption caused by a possible coating effect is reduced: soluble coatings are removed from the particles and the effect of insoluble coatings is reduced because of the low relative refractive index of these coatings compared to the liquid (Hitzenberger and Tohno, 2001). In the extended
Table 3. Temperature steps and residence times for the NIOSH870 protocol (Panteliadis et al., 2015; Birch and Cary, 1996).

\begin{tabular}{lrr}
\hline $\begin{array}{l}\text { Carrier } \\
\text { gas }\end{array}$ & $\begin{array}{r}\text { Temperature } \\
\left({ }^{\circ} \mathrm{C}\right)\end{array}$ & $\begin{array}{r}\text { Residence } \\
\text { time }(\mathrm{s})\end{array}$ \\
\hline $\mathrm{He}$ & 310 & 80 \\
$\mathrm{He}$ & 475 & 60 \\
$\mathrm{He}$ & 615 & 60 \\
$\mathrm{He}$ & 870 & 90 \\
$\mathrm{He}+\mathrm{O}_{2}$ & 550 & 45 \\
$\mathrm{He}+\mathrm{O}_{2}$ & 625 & 45 \\
$\mathrm{He}+\mathrm{O}_{2}$ & 700 & 45 \\
$\mathrm{He}+\mathrm{O}_{2}$ & 775 & 45 \\
$\mathrm{He}+\mathrm{O}_{2}$ & 850 & 45 \\
$\mathrm{He}+\mathrm{O}_{2}$ & 870 & 120 \\
\hline
\end{tabular}

technique (Wonaschütz et al., 2009) the sphere is illuminated with a halogen light source equipped with three interference filters $(450,550$ and $650 \mathrm{~nm})$ and the wavelength-dependent light signal is recorded with a photodiode. The contributions of $\mathrm{BC}$ and $\mathrm{BrC}$ to the absorption signal are separated in an iterative procedure using calibration curves obtained with a proxy for BC (Elftex 124, Cabot Corp.) and a proxy for BrC (humic acid sodium salt, Acros Organics, no. 68131044). 


\subsection{Raman spectroscopy}

In this study a confocal Raman microscope (Horiba Jobin Yvon LabRAM 800HR) was used. The Raman microscope was equipped with a $632.8 \mathrm{~nm}$ HeNe laser (maximum output $<20 \mathrm{~mW}$ ) and a charge-coupled device (CCD) camera (Peltier cooled at $-60^{\circ} \mathrm{C}$ ). The laser beam was focused on the sample with a $20 \times$ magnification objective (CF Plan, $20 \times / 0.35$, WD $20.5 \mathrm{~mm}$, Nikon). The spectra were calibrated with the Rayleigh line at $0 \mathrm{~cm}^{-1}$ and the silicon peak at $521 \mathrm{~cm}^{-1}$. The laser power was reduced to $10 \%$ for analyzing black samples and $25 \%$ for brown samples to prevent thermal destruction of the material. All instrument settings (grating 300 lines per $\mathrm{mm}, 3-4 \mathrm{~cm}^{-1}$ resolution; confocal hole $1000 \mu \mathrm{m}$; acquisition time $5 \mathrm{~s}$ with 30 accumulations) were chosen after a set of test measurements to provide the best signal-to-noise ratio for the analysis. As the samples burned off partially at the $775^{\circ} \mathrm{C}$ temperature step in the ECOC analyzer, the Raman spectra were recorded only for the first seven temperature steps.

The spectra were recorded in the range from 200 to $2000 \mathrm{~cm}^{-1}$ at four measurement points at three positions for each sample to account for possible variations within a filter sample. The averaged spectra for each filter were analyzed using OriginPro2016, which has built-in functions for baseline correction. Baselines were fitted with a B-spline function based on approximately 20 anchor points. After subtraction of the baseline, the spectra were fitted with five curves (four Lorentzian, one Gaussian; see Table 1). As initial values for the fit, the band positions obtained by Sadezky et al. (2005) and listed above (Table 1) were used. The standard deviations of the mean spectra were used in the fitting software as weighting of the fit.

\subsection{TEM - transmission electron microscopy}

A $200 \mathrm{kV}$ transmission electron microscope (TEM) Philips CM200 equipped with a Gatan ${ }^{\mathrm{TM}}$ Orius CCD camera was used to analyze the nanostructure of the original and the heated samples. Single filter fibers were separated from the samples and placed onto holey carbon films or between copper grids to facilitate studying freestanding soot particles. High-resolution microscopic images and diffraction patterns of particles deposited at the lateral edges of the fibers were taken. Intensity profiles of the diffraction patterns were obtained by both azimuthal integration along rings and background correction using PASAD-tools (Gammer et al., 2010). For comparison a simulated profile of graphite was calculated with JEMS software (Stadelmann, 2004).

\subsection{UV-VIS spectroscopy}

A LAMBDA 750 UV-VIS spectrometer (PerkinElmer, Waltham, Massachusetts, US), equipped with a tungsten and a deuterium lamp, was used to measure the diffuse re- flectance of the samples. Reflectance measurements were carried out from 800 to $200 \mathrm{~nm}$ with an interval of $1 \mathrm{~nm}$. At $319.2 \mathrm{~nm}$ the instrument switches from the tungsten (visible) to the deuterium (UV) lamp. For the measurement the original and heated samples were put into quartz vials without any liquid. The diffusely reflected light from the filter punches was collected with a $60 \mathrm{~mm}$ integrating sphere and detected with a photomultiplier. Absorbance spectra where calculated with the Kubelka-Munk equation (Kubelka and Munk, 1931) from the measured reflectance spectra. Although the Kubelka-Munk theory was developed originally for powder samples, its applicability to aerosol filter samples was shown by Aryal et al. (2014).

Absorbance spectra were calculated from the measured reflection signals $R_{\infty}(\lambda)$ using the Kubelka-Munk function:

$\mathrm{K}-\mathrm{M}(\lambda)=\frac{\left(1-R_{\infty}(\lambda)\right)^{2}}{2 R_{\infty}(\lambda)}$,

where $\mathrm{K}-\mathrm{M}(\lambda)$ is proportional to the absorbance, assuming infinite sample thickness. The spectra were corrected for background signals obtained from three filter blanks.

\section{Results and discussion}

\subsection{Thermal-optical analysis}

In the thermal-optical analysis most of the carbon of the black sample evolves in the $\mathrm{He}+\mathrm{O}_{2}$ phase. Throughout the successive heating steps, the laser reflectance signal remains relatively constant until EC oxidizes (Fig. 2). On the other hand, most of the carbon of the brown sample evolves in the He phase (Fig. 3). The laser reflectance signal decreases during the first three temperature steps, indicating a pyrolysis of the organic material. The signal starts to increase slightly at the last temperature step $\left(870^{\circ} \mathrm{C}\right)$ in $\mathrm{He}$ and increases rapidly at $625^{\circ} \mathrm{C}$ after $\mathrm{O}_{2}$ is added, indicating the combustion of initial EC and/or pyrolyzed OC (PC). The laser signal reaches its initial value at the end of the $700{ }^{\circ} \mathrm{C}$ temperature step; therefore approximately half of the carbon signal in the oxidizing atmosphere is assigned to OC following the normal procedure of the thermal-optical analysis method. Results from EC and OC measurements are summarized in Table 3. Figures 2 and 3 show full thermograms of a black and a brown sample.

\subsection{Black and brown carbon}

Figure 4 shows the change in $\mathrm{BC}$ and $\mathrm{BrC}$ during the thermal-optical analysis. The changing $\mathrm{BC}$ content of the sample is qualitatively consistent with the interpretation of the laser signal in the thermal-optical analysis: BC in the black sample decreases somewhat during the whole analysis cycle, while $\mathrm{BrC}$ is below the detection limit for each temperature step. 


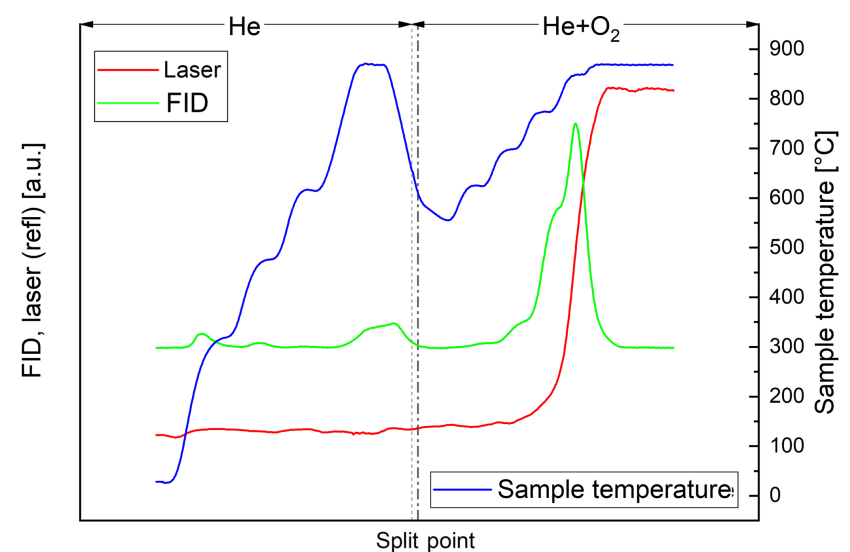

Figure 2. Thermogram of the black sample. The blue line is the temperature measured at the position of the sample, the red line the laser reflectance signal and the green line the signal of the flame ionization detector (FID), which is proportional to the amount of carbon leaving the filter. The split point was set at the point where the laser signal reached its initial value. The FID signal before the split point (broken line) is assigned to $\mathrm{OC}$ and after the split point to EC. The dotted line separates the inert and oxidizing phases.

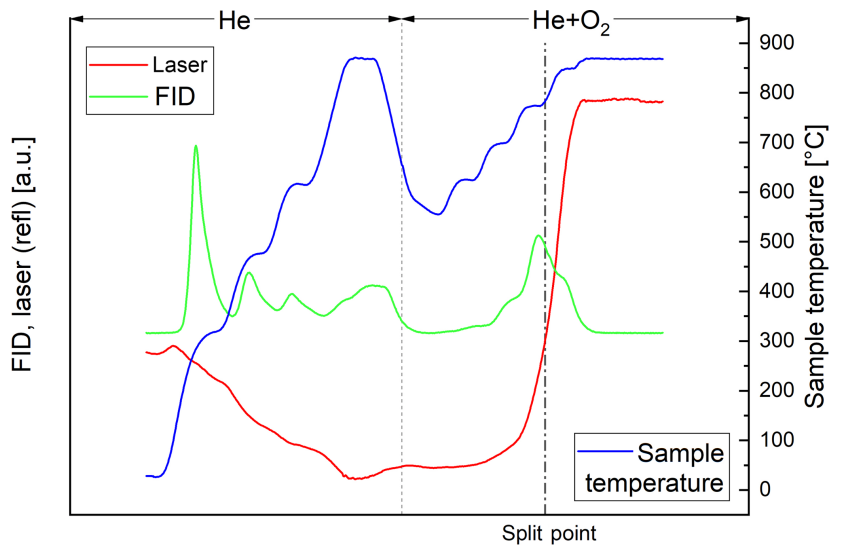

Figure 3. Thermogram of the brown sample. The blue line is the temperature measured at the position of the sample, the red line the laser reflectance signal and the green line the signal of the flame ionization detector (FID), which is proportional to the amount of carbon leaving the filter. The split point was set at the point where the laser signal reached its initial value. The FID signal before the split point (broken line) is assigned to OC and after the split point to EC. The dotted line separates the inert and oxidizing phases.

For the brown sample, $\mathrm{BrC}$ decreases continuously during the whole He mode, while $\mathrm{BC}$ increases over the He mode up until $870{ }^{\circ} \mathrm{C}(\mathrm{He})$ and decreases in the $\mathrm{He}+\mathrm{O}_{2}$ mode. These findings confirm that $\mathrm{BC}$ is built during the thermal-optical analysis of an organic-carbon-containing sample.

Table 4 summarizes the composition of the original brown and black samples regarding their $\mathrm{EC}, \mathrm{OC}, \mathrm{BC}$ and $\mathrm{BrC}$ content: the black sample consists mainly of $\mathrm{EC}$ or $\mathrm{BC}$ with a negligible amount of $\mathrm{BrC}$. On the contrary, the brown sam-

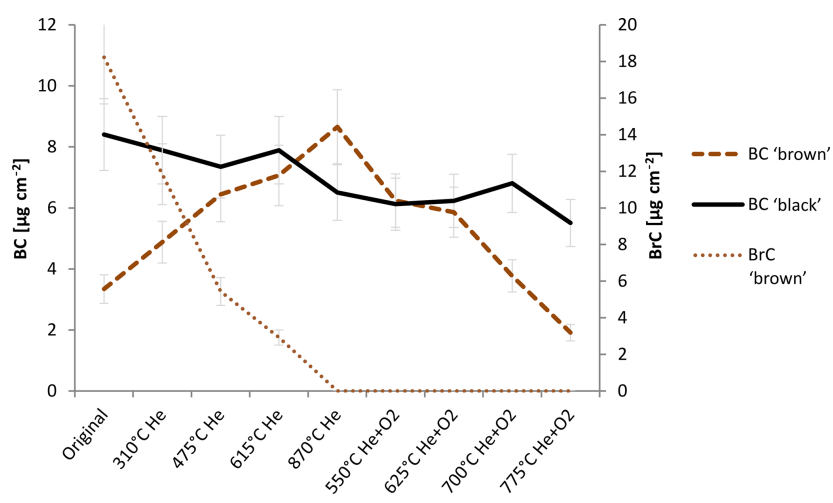

Figure 4. Change in $\mathrm{BC}$ and $\mathrm{BrC}$ measured with the IS method during heating according to the NOSH870 protocol measurement for the black and the brown sample. $\mathrm{BC}$ brown and $\mathrm{BrC}$ brown refer to the amount of $\mathrm{BC}$ and $\mathrm{BrC}$ of the brown sample; $\mathrm{BC}$ black refers to the amount of $\mathrm{BC}$ of the black sample. BrC of the black sample is below detection limit for the original and the heated samples, respectively. The error bars indicate deviations of $\pm 14 \%$. Laboratory intern test measurements gave variations in this range for filter samples measured in the integrating sphere.

Table 4. Results of thermal-optical and integrating-sphere measurements.

\begin{tabular}{lrr}
\hline & $\begin{array}{r}\text { Thermal-optical } \\
\text { measurement } \\
\text { EC/TC }\end{array}$ & $\begin{array}{r}\text { Integrating } \\
\text { sphere method } \\
\text { BC/LAC }\end{array}$ \\
\hline Black & 0.85 & 0.99 \\
Brown & 0.09 & 0.11 \\
\hline
\end{tabular}

ple contains only about $10 \% \mathrm{EC}$ or $\mathrm{BC}$ and approximately $90 \% \mathrm{BrC}$.

\subsection{Raman spectra}

The change in the Raman spectra due to the heating process in the thermal-optical instrument is shown in Figs. 5 and 6. For a better comparison the spectra are normalized to the maximum of the $G$ peak. While the maxima of the $D$ and $G$ peak do not change for the black sample, the spectra of the brown sample show a relative increase in the $\mathrm{D}$ peak for samples heated at $870^{\circ} \mathrm{C}$ in $\mathrm{He}$. The peak does not increase continuously over the whole heating process, which indicates a significant structural change especially at this temperature step. Following the interpretation of Ferrari and Robertson (2000) and its application to soot samples by Commodo et al. (2016), Ess et al. (2016) and Ivleva et al. (2007a, b), this increase in the $\mathrm{D}$ peak indicates an increased amount of polyaromatic rings in the sample which can be associated with a higher degree of ordering.

For a better comparison, the spectra of the black and brown original samples and samples heated to $870^{\circ} \mathrm{C}$ in $\mathrm{He}$ are shown in Fig. 7. The D peak of the brown heated sample 


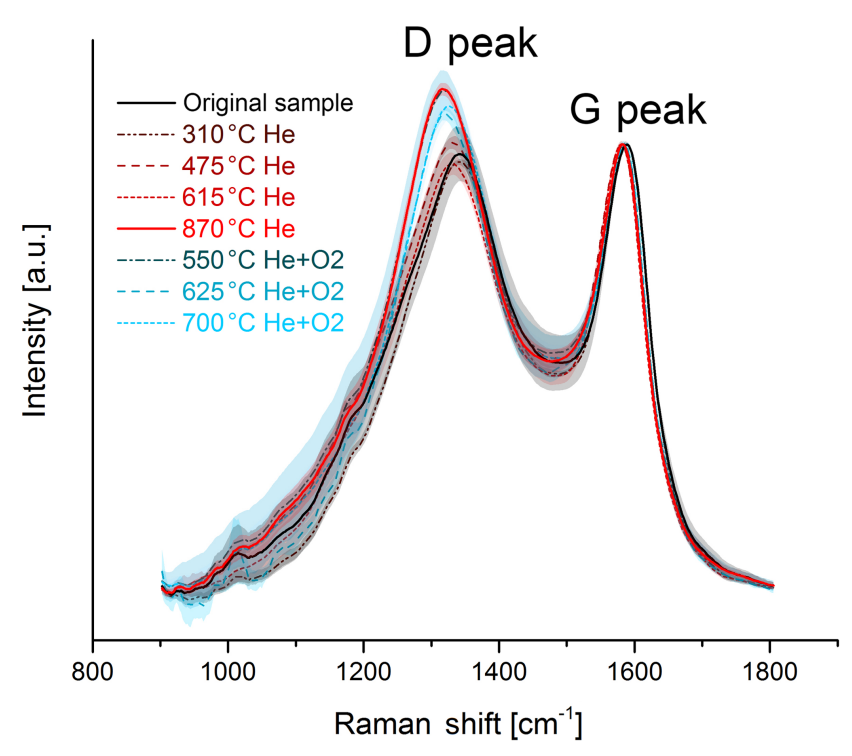

Figure 5. Raman spectra of the original and the heated brown sample. The black and red solid lines represent the original sample and the sample heated to $870^{\circ} \mathrm{C}$ in $\mathrm{He}$, where a significant structural change occurs. The mean spectra are smoothed and normalized to the maximum of the $\mathrm{G}$ peak. The shaded areas represent the standard deviations of the mean spectra.

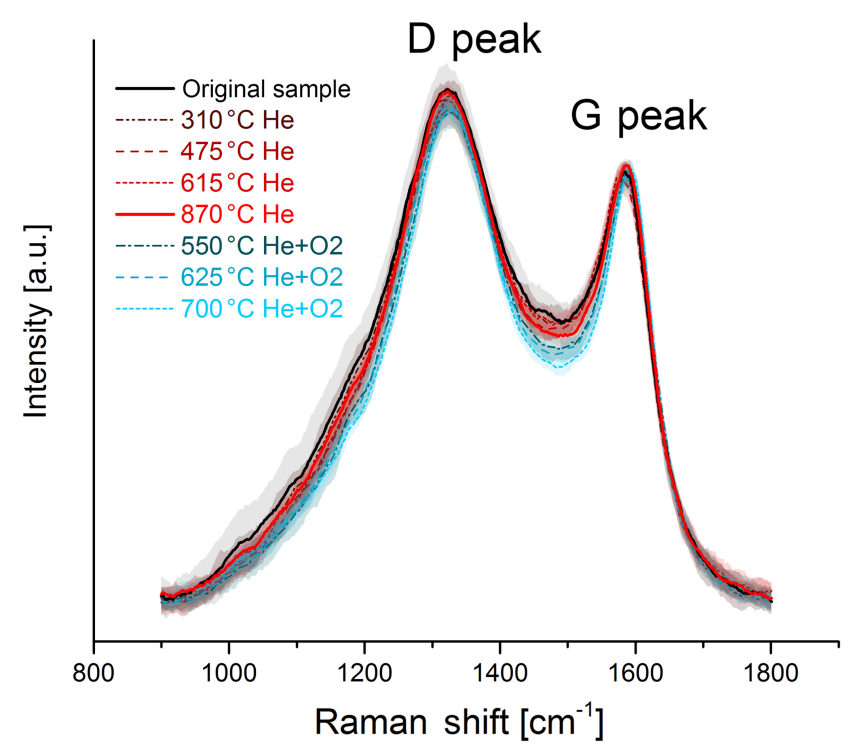

Figure 6. Raman spectra of the original and the heated black sample. The black and red solid lines represent the original sample and the sample heated to $870^{\circ} \mathrm{C}$ in $\mathrm{He}$. In contrast to the spectra of the brown sample, no significant change in the D-peak height due to heating is visible here. The mean spectra are smoothed and normalized to the maximum of the $\mathrm{G}$ peak. The shaded areas represent the standard deviations of the mean spectra.

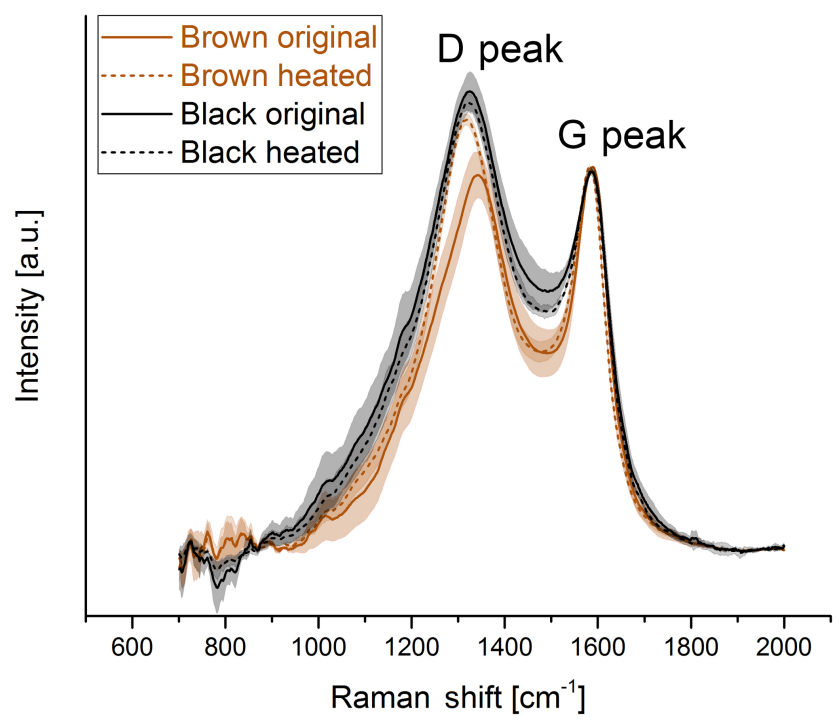

Figure 7. Comparison of the Raman spectra of the original and heated $\left(870^{\circ} \mathrm{C} \mathrm{He}\right)$ samples for the brown and the black sample. The $\mathrm{D}$ peak of the spectrum of the brown sample reaches the height of the D peak of the black sample when the sample is heated to $870^{\circ} \mathrm{C}$ in $\mathrm{He}$.

reaches nearly the height of the $\mathrm{D}$ peak of the black original and heated samples.

Figure 8 shows the five-curve fits of these four spectra. All fits were performed on the smoothed and averaged versions of the spectra. It is obvious that there is no significant change in the five peaks between the original and heated black sample. However, the spectra of the brown sample show a significant change at the $\mathrm{D} 4_{\text {fit }}$ peak $\left(\approx 1200 \mathrm{~cm}^{-1}\right)$ and the $\mathrm{D} 1_{\text {fit }}$ peak $\left(\approx 1350 \mathrm{~cm}^{-1}\right)$, when the sample is heated to $870^{\circ} \mathrm{C}$ in He: while the $\mathrm{D} 4_{\text {fit }}$ peak (which is related to $\mathrm{C}=\mathrm{C}$ double bonds, Sadezky et al., 2005) decreases, the $\mathrm{D} 1_{\text {fit }}$ peak (related to graphene layer edges, Sadezky et al., 2005) increases. This implies that the material in the heated sample contains fewer $\mathrm{C}=\mathrm{C}$ double bonds and more graphene layer edges compared to the original brown sample.

Possible explanations could be a decomposition and evolution of molecules with $\mathrm{C}=\mathrm{C}$ bonds (e.g., polyenes) and a coincident fragmentation of preexisting graphene layers or a transformation of molecules with $\mathrm{C}=\mathrm{C}$ bonds into new small graphene layers. Both scenarios would lead to a higher amount of graphene layer edges (and an increased $\mathrm{D} 1_{\text {fit }}$ peak) and a lower amount of $\mathrm{C}=\mathrm{C}$ bonds (and a decreased $\mathrm{D} 4_{\mathrm{fit}}$ peak).

TEM images (see below) show that the ordering in the brown sample increases when it is heated to $870^{\circ} \mathrm{C}$ in $\mathrm{He}$. The UV-VIS spectra (see below) show a decreasing absorption coefficient which requires a growth instead of a fragmentation of the conjugated orbitals in the material. Both findings are more consistent with the second process. 

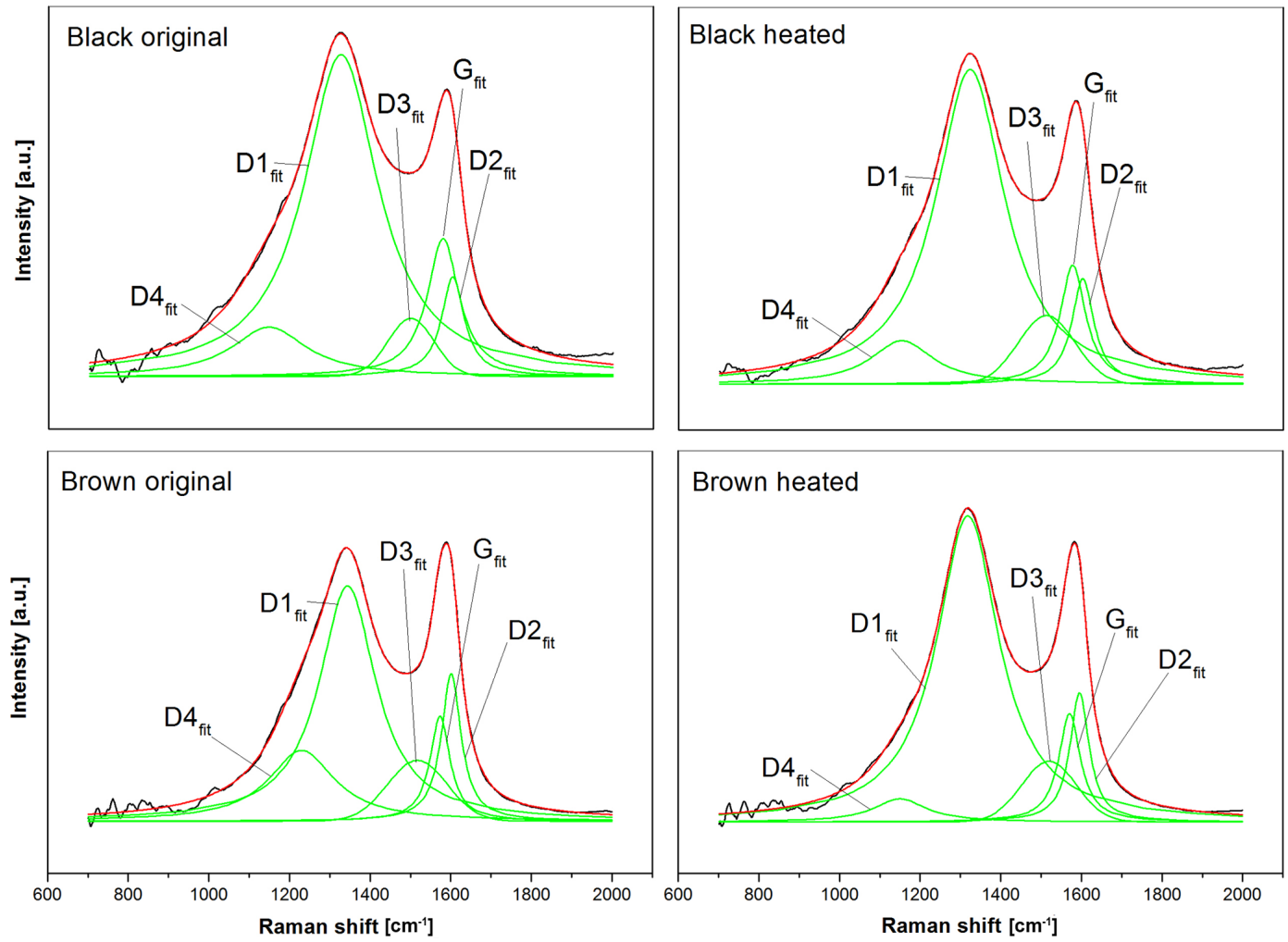

Figure 8. Five-curve fits of the original and heated $\left(870^{\circ} \mathrm{C} \mathrm{He}\right)$ spectra using the band positions and curve shapes of Sadezky et al. (2005). The black lines are the measured intensities, the green lines the five fitting curves $\left(\mathrm{D} 1_{\text {fit }}-\mathrm{D} 4_{\mathrm{fit}}\right.$ and $\left.\mathrm{G}_{\mathrm{fit}}\right)$ and the red lines the fitted spectra. The fitted curves of the black sample are similar before and after heating, while the $\mathrm{D} 1_{\text {fit }}$ and $\mathrm{D} 4_{\text {fit }}$ of the brown sample change.

\subsection{TEM - transmission electron microscopy}

The TEM images of the black and brown samples show entirely different morphologies. The soot in the black sample consists of agglomerates of spherical primary particles with diameters of about $20 \mathrm{~nm}$ (Fig. 9). The primary particles show an onion-like graphitic structure as it is also reported by Sadezky et al. (2005) and Kim et al. (2015). From the TEM images of the brown sample an ordered internal structure is not visible. The particles seem to consist of an oily substance (described as "condensed organic species" by Moore et al., 2014) which adheres well to the filter fibers (Fig. 10). However, analysis of the electron diffraction patterns indicates a small degree of ordering (see below).

After heating to $870^{\circ} \mathrm{C}$ under helium atmosphere, the black sample shows the same graphitic-like structure as the original black sample. However, the brown heated $\left(870^{\circ} \mathrm{C}\right.$ $\mathrm{He}$ ) sample seems to have a more ordered internal structure in the form of layers than its original version as indicated by stronger noticeable local fringe-like contrast (Fig. 11).

The electron diffraction patterns (Fig. 12) of both heated and original samples show rings with maxima at $2.8 \mathrm{~nm}^{-1}$ (A), $4.9 \mathrm{~nm}^{-1}$ (B) and $8.4 \mathrm{~nm}^{-1}$ (C). The positions of the rings are very similar to those of simulated graphite with randomly oriented small graphitic domains (cf. inset in Fig. 13).
Therefore we conclude that the ring A at $2.8 \mathrm{~nm}^{-1}$ can be related to the layer distance of graphite and the ring $\mathrm{B}$ at $4.9 \mathrm{~nm}^{-1}$ to the (100) or (101) planes of graphite. All rings appear in the diffraction patterns of both the black and the brown samples in Fig. 12, but they are broader for the brown original sample. The latter result is demonstrated more clearly in the intensity profiles calculated by azimuthal integration along rings (Fig. 13) and indicates that the brown original sample is less ordered than the black sample. This finding is also consistent with the Raman spectra and the realspace TEM images. Based on the comparison of the positions and profiles of the experimental peaks to the simulated ones, it is concluded that all samples contain small graphitic-like atomic arrangements. The tendency of the maximum A to larger diffraction vectors by thermal treatment of the brown sample refers to a slight reduction of the distance of graphitic layers by heating resembling that of the black one.

The quantitative evaluation of the peak width by the full width at half maximum (FWHM) is displayed for the different samples in Fig. 14. In the case of the brown sample the FWHM of ring B decreases by $30 \%$ as a consequence of heating. This result can be interpreted as an increase in the coherently scattering domain size (Fultz and Howe, 2001) and an increased degree of structural order during heating. This interpretation holds also for the other peaks; for exam- 

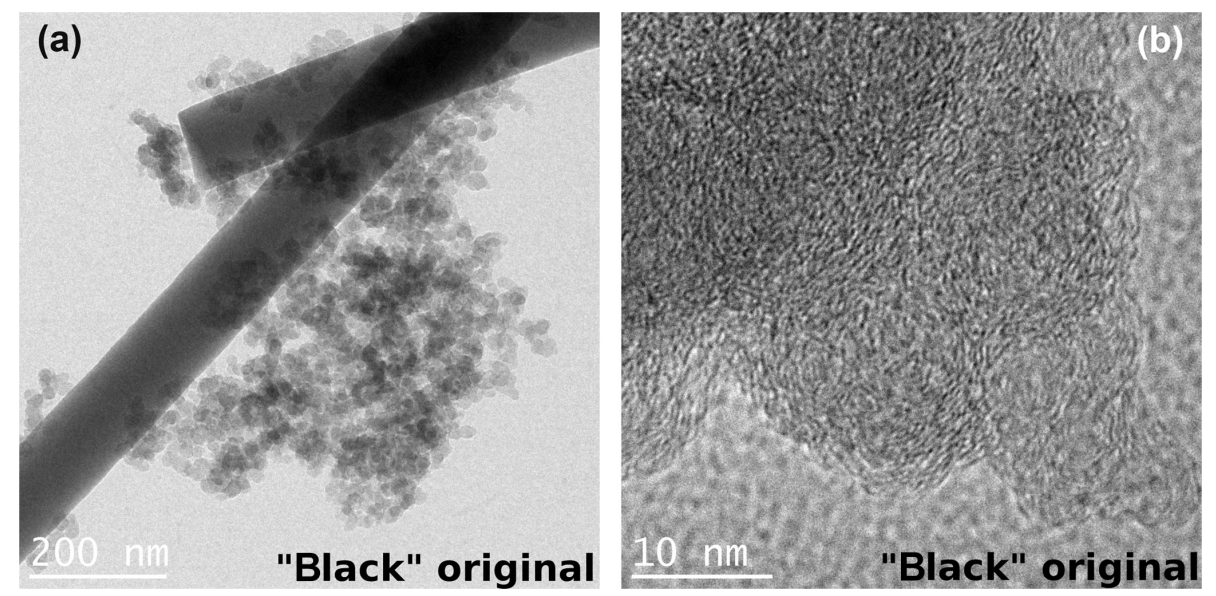

Figure 9. TEM images of the black original sample with two different magnifications. The black sample consists of agglomerates of spherical primary particles. The higher magnification shows an onion-like structure of the single spheres as reported by Sadezky et al. (2005) and Kim et al. (2015).
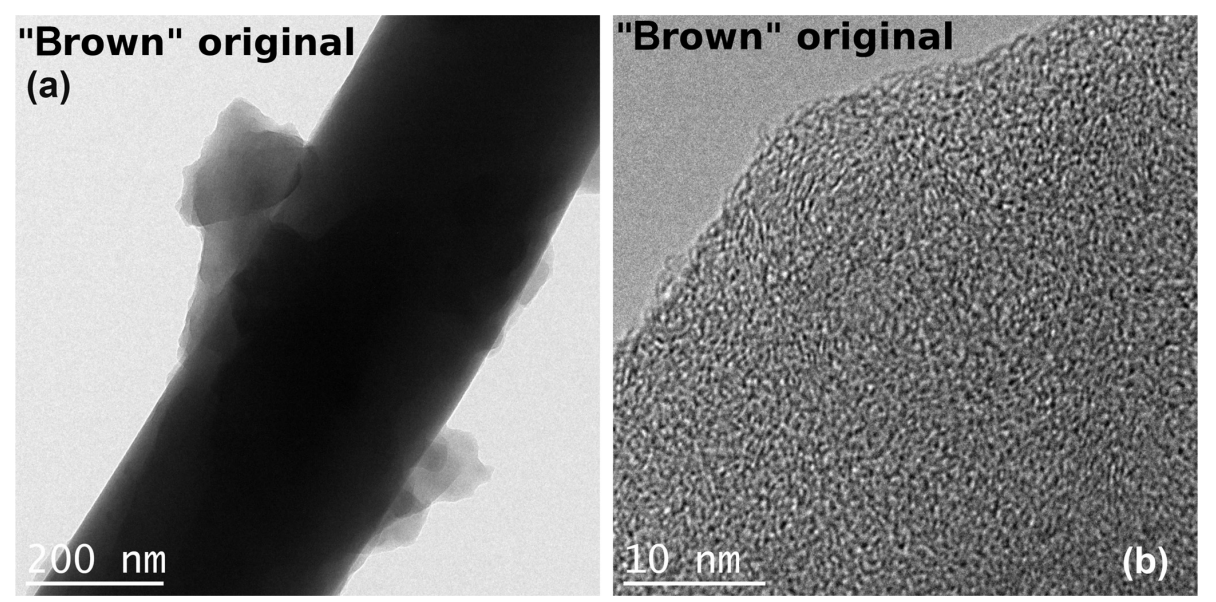

Figure 10. TEM images of the brown original sample taken at two different magnifications. The brown sample consists of unstructured droplets. The disordered structure is visible in the right image.

ple, the FWHM value of peak A at $2.8 \mathrm{~nm}^{-1}$ changes from $0.54 \pm 0.05$ to $0.45 \pm 0.04 \mathrm{~nm}^{-1}$ by heating up to $870^{\circ} \mathrm{C}$ (Figs. 13 and 14).

Based on these FWHM values and using the Scherrer equation (Fultz et al., 2001) the size of the coherently scattering domains (in the direction perpendicular to the (002) layers) changes from about 1.6 to $2 \mathrm{~nm}$ as a consequence of heating. On the other hand, the FWHM of the black sample does not change and neither does the internal structure of the material (Figs. 13 and 14). Black original and heated samples were found to have coherently scattering domains with sizes of about $2.2 \mathrm{~nm}$ from which we conclude a slight difference in the structural ordering between the black and the brown heated sample. The changes in the graphitic domain size of the brown sample during heating confirm the findings of the Raman measurements but the temperature dependence is still different. As shown in Fig. 14 the FWHM of the brown sam- ple decreases already at temperatures below $870^{\circ} \mathrm{C}$. This is in contrast to the Raman spectra, where a sudden change in the shape of the curves occurs at $870^{\circ} \mathrm{C}$ in $\mathrm{He}$. The cause for this difference is not completely clear. A possible explanation might be a reorientation and alignment of existing clusters and layers and therefore an increase in the size of coherently scattering domains at temperatures below $870^{\circ} \mathrm{C}$. This would not necessarily change the Raman signal since the structure within the clusters can be kept unchanged and the existing clusters would only rotate, rearrange and align.

\subsection{UV-VIS spectroscopy}

Figure 15 shows the wavelength dependence of light absorption by the brown and black original and heated samples. The wavelength dependence of the brown sample changes during the heating process. The absorption spectra for the black 

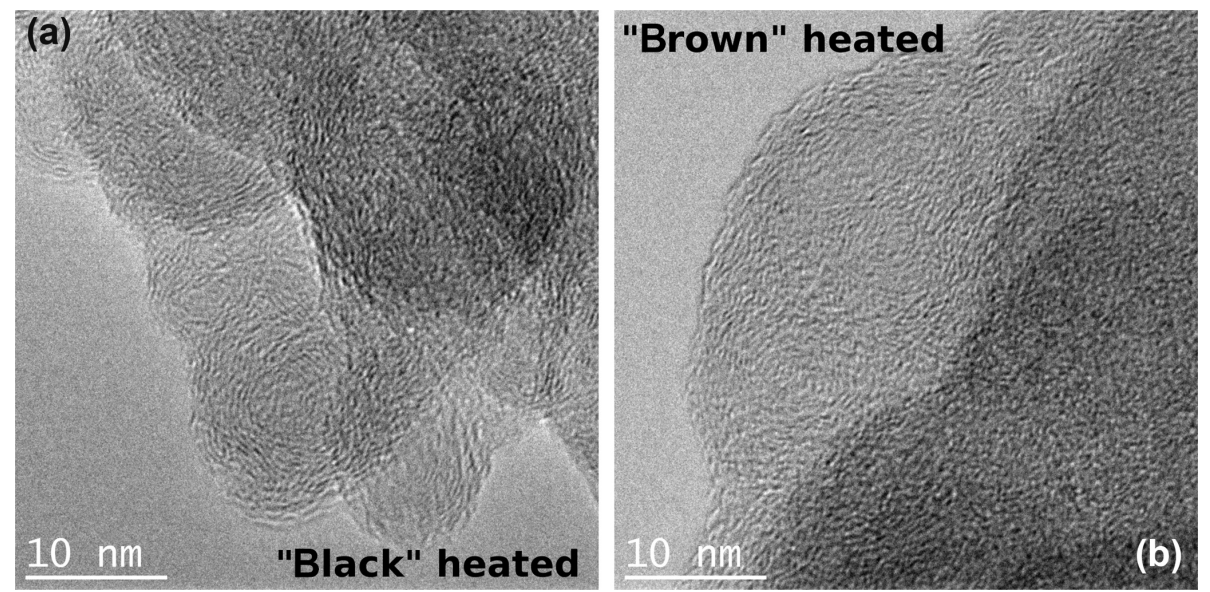

Figure 11. TEM images of the black (a) and brown (b) heated $\left(870^{\circ} \mathrm{C} \mathrm{He}\right)$ samples taken at high magnifications. An increased ordering of the heated brown sample can be discerned, while the structure of the black heated sample does not change visibly in comparison to the original sample.

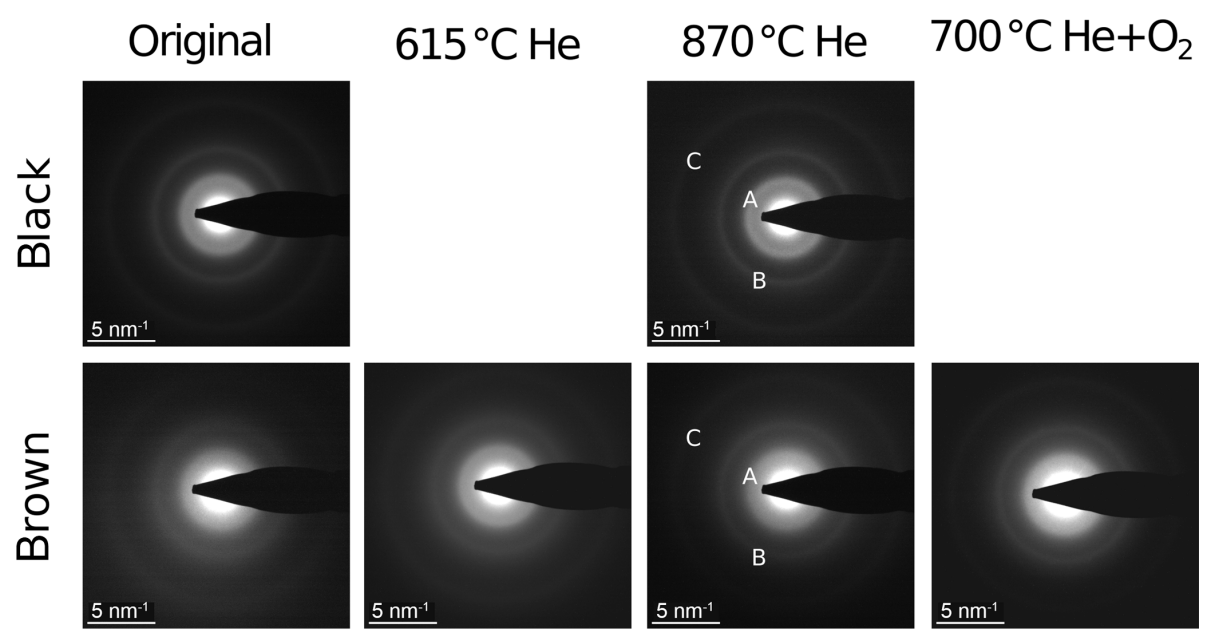

Figure 12. Electron diffraction patterns of black and brown samples; original and heated. A, B and C indicate the ring maxima at $2.8,4.9$ and $8.4 \mathrm{~nm}^{-1}$, respectively.

heated and original samples, however, do not change significantly, particularly not in one distinct direction. The spectrum of the brown original sample has a strong wavelength dependence, but during the heating process this spectrum changes and becomes more and more similar to the spectra of the black samples.

The wavelength dependence of the absorption was fitted using the Ångström power law:

$\ln \left(I / I_{0}\right)=K \cdot \lambda^{\alpha}$,

where $I_{0}$ is the incident intensity, $I$ the reflected intensity, $\alpha$ the Angström exponent, $\lambda$ the wavelength and $K$ a constant. Figure 16 shows the absorption spectra for the brown original and heated samples with the spectrum for the black original sample for comparison. The Ångström exponents of the respective curves are given in the figure.
The spectrum of the original brown sample starts with an Ångström exponent of $\alpha=-1.79$. During the heating process the wavelength dependence decreases and reaches values of $\alpha \approx-0.63$ after the heating step of $870^{\circ} \mathrm{C}$ in $\mathrm{He}$, which is even lower than the Angström exponent for the black original sample $(\alpha=-0.92)$.

The low Ångström exponent $(-0.35)$ of the sample heated to $775^{\circ} \mathrm{C}$ in $\mathrm{O}_{2}$ might suffer from measurement uncertainties. At this heating stage, most of the absorbing material has already been burned off the filter and the K-M absorption signals are already very small.

This decrease in the Ångström exponent for the brown sample indicates an increase in BC, which is consistent with the findings of the IS measurements. At the heating stage of $870^{\circ} \mathrm{C}$ in $\mathrm{He}$ and after this stage, the Ångström exponent is even lower than for the black original sample. 


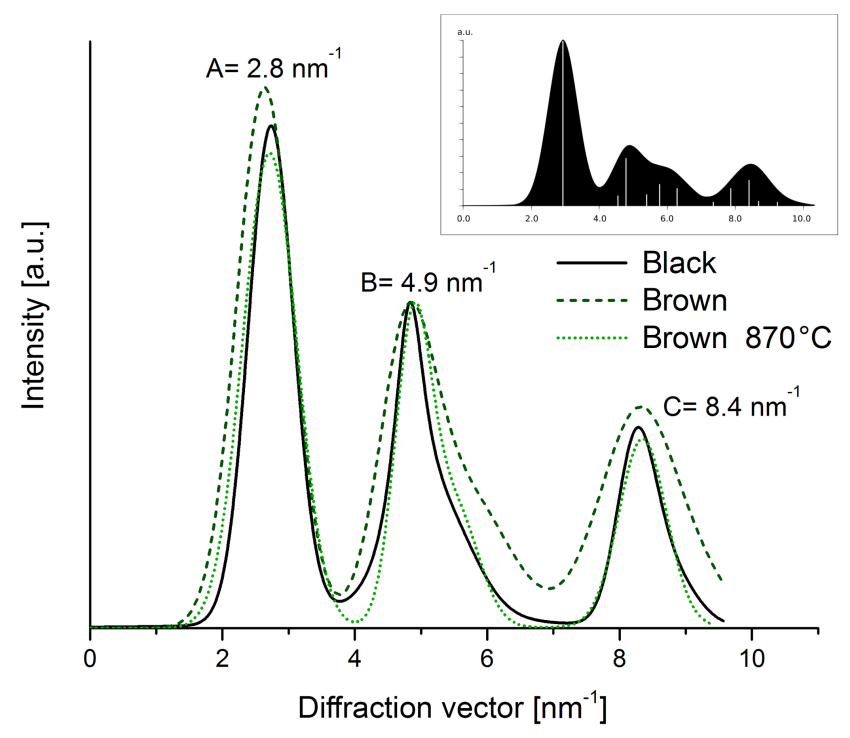

Figure 13. Intensity profiles of diffraction patterns taken from the black and brown original sample and the brown heated $\left(870^{\circ} \mathrm{C} \mathrm{He}\right)$ sample. The intensities of all three samples were normalized to the peak intensity at $4.9 \mathrm{~nm}^{-1}$. The image in the right corner shows the simulation for a graphitic material with small and randomly oriented graphitic clusters.

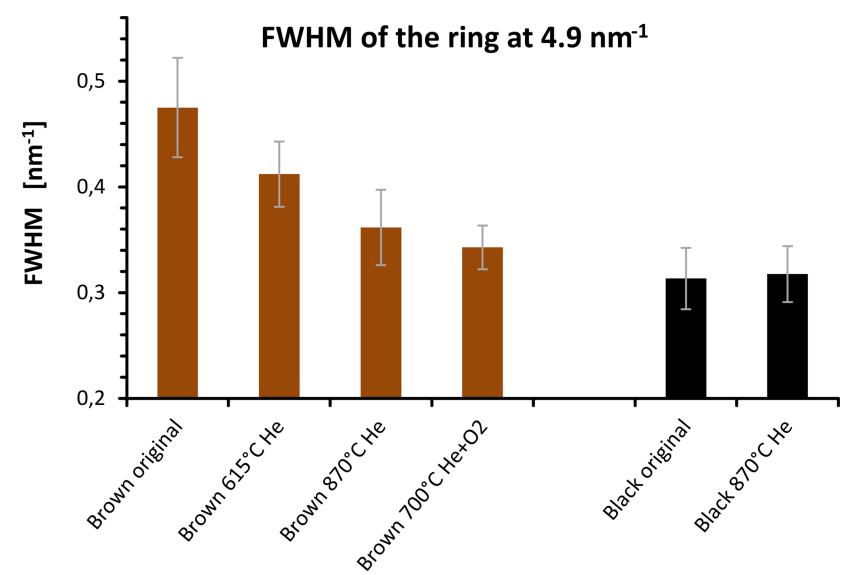

Figure 14. FWHM of the $4.9 \mathrm{~nm}^{-1}$ maximum of electron diffraction of the original and heated samples for selected temperatures. The FWHM of the brown sample decreases during the heating process and reaches values near the FWHM of the black sample after heating at $870^{\circ} \mathrm{C}$ in $\mathrm{He}$.

Absorption Ångström exponents depend on both the refractive index and on the size of the absorbing particles (Bohren and Huffman, 1998). Absorption by small particles (in the Rayleigh regime) has a stronger wavelength dependence than that by larger particles in the Mie scattering size range. The observed behavior of the Ångström exponents could be caused by the different sizes and shapes of the particles of the black sample compared to particles in the brown sample. As we saw from the TEM images, the particles of the

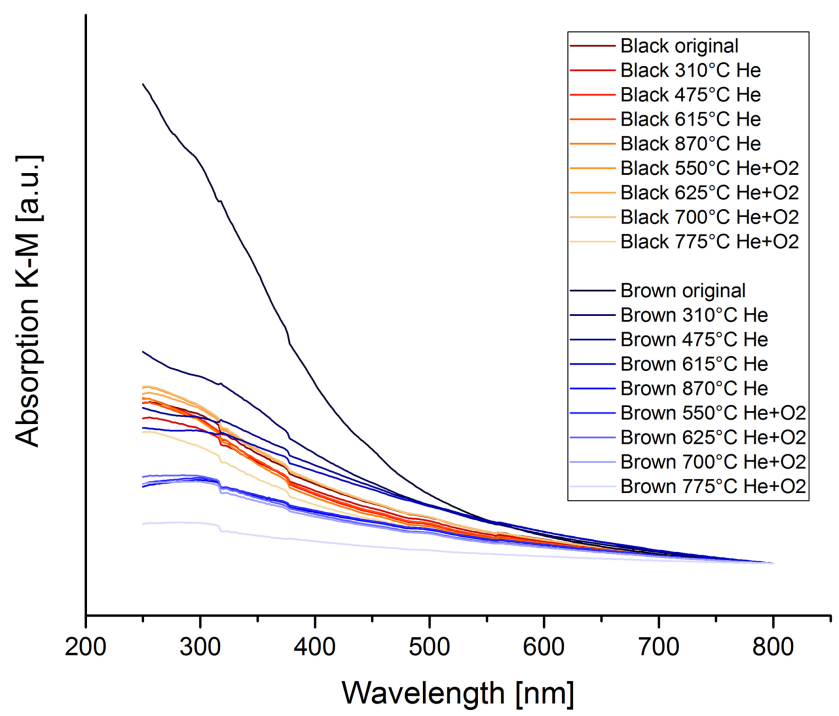

Figure 15. UV-VIS spectra for the black and brown heated and original samples. The spectra are normalized at $800 \mathrm{~nm}$ for better comparison. The wavelength dependence does not change significantly during the thermal-optical heating process for the black sample, while the wavelength dependence decreases continuously for the brown sample.

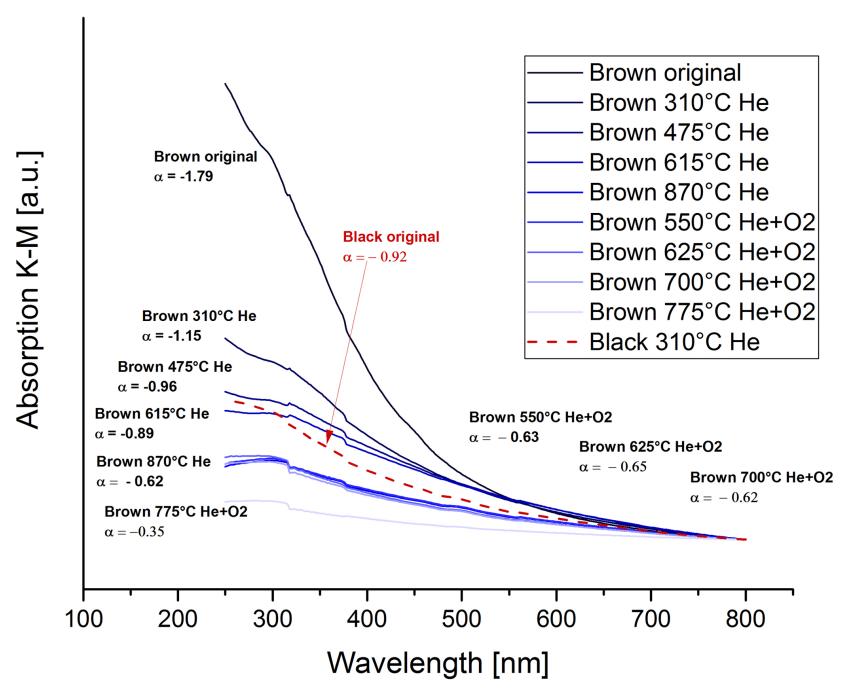

Figure 16. UV-VIS spectra for the brown original and heated samples and corresponding Ångström exponents. The dashed red line shows the spectrum of the black original sample for comparison.

black sample consist of agglomerates of spherical primary particles with diameters of about $20 \mathrm{~nm}$, whereas the particles in the brown sample are larger than these primary particles. This large size difference is not substantially changed due to heating. 


\section{Conclusion}

From the various analyses a change in structure of the brown sample during thermal analysis can be clearly seen. For the black sample which consists of agglomerates of spherules with graphitic-like structure no such change occurs. These findings are supported by all analysis techniques employed here (UV-VIS measurements, Raman spectroscopy, TEM and IS). The interpretation of the data of the brown sample, however, is quite complex and in some cases more than one interpretation might be possible. The Raman spectra show that the structure of the brown sample changes significantly at $870^{\circ} \mathrm{C}$ in the $\mathrm{He}$ atmosphere. According to Ferrari and Robertson (2000) the relative increase in the D peak in the spectra indicates an increase in clustered aromatic rings in the material. Also the five-curve fits of the spectra suggest that new small graphitic layers could be formed during the $870^{\circ} \mathrm{C}$ heating step. The TEM measurements confirm the increase in ordering in the brown sample since the FWHM of the electron diffraction maxima, e.g., at $4.9 \mathrm{~nm}^{-1}$, decreases when the sample is heated. Consequently, an increase in domain size from 1.6 to $2 \mathrm{~nm}$ can be estimated for the original and heated brown sample, respectively. The FWHM, i.e., the level of ordering and the domain size, stays nearly constant over the subsequent cooling and reheating process in the $\mathrm{He}+\mathrm{O}_{2}$ atmosphere. Although the FWHM value, the coherently scattering domain size and the layer distance at $870{ }^{\circ} \mathrm{C}$ reach nearly the same values as those of the black sample, slight structural differences of the brown and black sample are still present and can be, for example, related to the more perfect stacking of graphene-like layers in the black sample.

Likewise, the wavelength dependence of the UV-VIS spectra of the brown sample resembles the wavelength dependence of the black sample when the sample is heated to $870{ }^{\circ} \mathrm{C}$ in He. The Ångström exponent stays constant during the subsequent heating steps in $\mathrm{He}+\mathrm{O}_{2}$.

So all of the applied analysis techniques agree that the structure of the brown sample resembles more or less the structure of the black sample when the sample is heated to $870^{\circ} \mathrm{C}$ in $\mathrm{He}$. All techniques also show that the structure does not change further during the subsequent heating steps.

For the last temperature step in the Helium phase $\left(870^{\circ} \mathrm{C}\right)$ the results of the different measurement techniques applied in this study are consistent among themselves. However, the findings for samples heated at lower temperatures are somewhat contradictory: while the Raman spectra change suddenly at $870^{\circ} \mathrm{C}$ in $\mathrm{He}$ and do not change significantly during the preceding temperature steps (highest temperature $615^{\circ} \mathrm{C}$ in $\mathrm{He}$ ), the decrease in the wavelength dependence and the darkening (i.e., the laser signal in the EC-OC analyzer) occur during the whole heating process. The change in the FWHM of the $4.9 \mathrm{~nm}^{-1}$ of the electron diffraction maximum and the formation of $\mathrm{BC}$ also occur continuously.

It is not unambiguously clear how the structural change proceeds during the first three heating steps. The optical mea- surement techniques suggest a continuous change, as the optical signals change continuously. The electron diffraction patterns also imply a continuous change. On the other hand, the Raman spectra clearly show that Raman sensitive structures do not change significantly during the first three heating steps, which indicates that no new graphene layers (i.e., a clustering of aromatics) are built. But the weakening of the wavelength dependence indicates a decrease in the optical band gap in the material, which might be due to an increasing size of polyaromatic and graphene-like structures, i.e., larger conjugated $\pi$ molecular orbitals.

Oxygen and hydrogen can leave the sample at temperatures above $250^{\circ} \mathrm{C}$ in $\mathrm{He}$ (Petzold et al., 2013; Chow et al., 2004). The free bonds could be incorporated in the remaining molecule and form conjugated double bonds and increase aromaticity, which would lead to the observed change in the UV-VIS spectra. Also oxygenated groups at the edges of the molecules have effects on the optical behavior: a decrease in oxygen leads to a darkening of the substance, i.e., weaker wavelength dependence. Both of these changes would explain the optical behavior of the sample but would not significantly affect the Raman spectra of soot.

Even though it is not unambiguously clear which differences in the structures lead to the conflicting results, our findings indicate that different physical-chemical processes occur at the lower temperatures in comparison to the $870^{\circ} \mathrm{C}$ (He) step. This is consistent with the findings of Yu and Yang (2002), who showed that the value of $\sigma$ of PC in some cases is not constant during a single thermal analysis.

Overall we conclude that the most significant and at the same time irreversible structural change of the pyrolyzed organic material in our samples happens at $870^{\circ} \mathrm{C}$ in $\mathrm{He}$ in the measurement protocol used here and that new graphenelike layers are built. We can only speculate, however, on the causes of the continuous darkening of the sample during the lower-temperature steps.

Data availability. Data can be accessed by contacting the corresponding author.

Author contributions. TH performed the conceptualization of the experimental setup, all measurements except TEM, the evaluation and interpretation of data and the preparation of the manuscript. CR performed the TEM measurements and wrote the TEM section. JCM contributed to discussions and provided input for TEM measurements. LF provided cooperation regarding UV-VIS measurements and wrote part of the UV-VIS methods section. HG contributed to discussions, provided input for the Raman and UV-VIS measurements, and acquired funding. RH performed the conceptualization, supervised, contributed to discussions, and provided extensive input to the text. 
Competing interests. The authors declare that they have no conflict of interest.

Acknowledgements. This work was supported by the Austrian Science Fund (FWF), grant P26040. The integrating-sphere technique was developed within the grant H-85/92 Hochschuljubiläumstiftung der Stadt Wien. We thank Karin Wieland for the valuable advice for the Raman measurements.

Financial support. This research has been supported by the Austrian Science Fund (FWF) (grant no. P26040).

Review statement. This paper was edited by Pierre Herckes and reviewed by Darrel Baumgardner and one anonymous referee.

\section{References}

Adachi, K. and Buseck, P. R.: Changes of ns-soot mixing states and shapes in an urban area during CalNex, J. Geophys. Res., 9, 3723-3730, https://doi.org/10.1002/jgrd.50321, 2013.

Adachi, K., Chung, S. H., and Buseck, P. R.: Shapes of soot aerosol particles and implications for their effects on climate, J. Geophys. Res., D15, 6469, https://doi.org/10.1029/2009JD012868, 2010.

Anderson, J. O., Thundiyil, J. G., and Stolbach, A.: Clearing the air. A review of the effects of particulate matter air pollution on human health, J. Med. Toxicol., 2, 166-175, https://doi.org/10.1007/s13181-011-0203-1, 2012.

Andreae, M. O. and Gelencsér, A.: Black carbon or brown carbon? The nature of light-absorbing carbonaceous aerosols, Atmos. Chem. Phys., 6, 3131-3148, https://doi.org/10.5194/acp-63131-2006, 2006.

Arnott, W. P., Moosmüller, H., Fred Rogers, C., Jin, T., and Bruch, R.: Photoacoustic spectrometer for measuring light absorption by aerosol. Instrument description, Atmos. Environ., 17, 28452852, https://doi.org/10.1016/S1352-2310(98)00361-6, 1999.

Aryal, R., Terman, P., and Voss, K. J.: Comparison of Two FilterBased Reflectance Methods to Measure the Light Absorption by Atmospheric Aerosols, J. Atmos. Ocean. Tech., 4, 923-929, https://doi.org/10.1175/JTECH-D-13-00131.1, 2014.

Birch, M. E. and Cary, R. A.: Elemental Carbon-Based Method for Monitoring Occupational Exposures to Particulate Diesel Exhaust, Aerosol Sci. Technol., 3, 221-241, https://doi.org/10.1080/02786829608965393, 1996.

Bladt, H., Ivleva, N. P., and Niessner, R.: Internally mixed multicomponent soot. Impact of different salts on soot structure and thermo-chemical properties, J. Aerosol Sci., 70, 26-35, https://doi.org/10.1016/j.jaerosci.2013.11.007, 2014.

Bohren, C. F. and Huffman, D. R.: Absorption and Scattering of Light by Small Particles, Wiley, New York, 1998.

Bond, T. C.: Spectral dependence of visible light absorption by carbonaceous particles emitted from coal combustion, Geophys. Res. Lett., 21, 4075-4078, https://doi.org/10.1029/2001GL013652, 2001.
Bond, T. C. and Bergstrom, R. W.: Light Absorption by Carbonaceous Particles. An Investigative Review, Aerosol Sci. Technol., 1, 27-67, https://doi.org/10.1080/02786820500421521, 2006.

Bondy, A. L., Bonanno, D., Moffet, R. C., Wang, B., Laskin, A., and Ault, A. P.: The diverse chemical mixing state of aerosol particles in the southeastern United States, Atmos. Chem. Phys., 18, 12595-12612, https://doi.org/10.5194/acp-18-125952018, 2018.

Brown, R. J. C., Beccaceci, S., Butterfield, D. M., Quincey, P. G., Harris, P. M., Maggos, T., Panteliadis, P., John, A., Jedynska, A., Kuhlbusch, T. A. J., Putaud, J.-P., and Karanasiou, A.: Standardisation of a European measurement method for organic carbon and elemental carbon in ambient air. Results of the field trial campaign and the determination of a measurement uncertainty and working range, Environ. Sci.-Pro. Imp., 10, 12491259, https://doi.org/10.1039/C7EM00261K, 2017.

Buseck, P. R., Adachi, K., Gelencsér, A., Tompa, É., and Pósfai, M.: Ns-Soot. A Material-Based Term for Strongly LightAbsorbing Carbonaceous Particles, Aerosol Sci. Technol., 7, 777-788, https://doi.org/10.1080/02786826.2014.919374, 2014.

Cappa, C. D., Onasch, T. B., Massoli, P., Worsnop, D. R., Bates, T. S., Cross, E. S., Davidovits, P., Hakala, J., Hayden, K. L., Jobson, B. T., Kolesar, K. R., Lack, D. A., Lerner, B. M., Li, S.-M., Mellon, D., Nuaaman, I., Olfert, J. S., Petäjä, T., Quinn, P. K., Song, C., Subramanian, R., Williams, E. J., and Zaveri, R. A.: Radiative absorption enhancements due to the mixing state of atmospheric black carbon, Science, 6098, 1078-1081, https://doi.org/10.1126/science.1223447, 2012.

Cavalli, F., Viana, M., Yttri, K. E., Genberg, J., and Putaud, J.-P.: Toward a standardised thermal-optical protocol for measuring atmospheric organic and elemental carbon: the EUSAAR protocol, Atmos. Meas. Tech., 3, 79-89, https://doi.org/10.5194/amt-3-792010, 2010.

Cheng, Y., Duan, F.-K., He, K.-B., Du, Z.-Y., Zheng, M., and Ma, Y.-L.: Intercomparison of thermal-optical method with different temperature protocols. Implications from source samples and solvent extraction, Atmos. Environ., 453-462, https://doi.org/10.1016/j.atmosenv.2012.07.066, 2012.

Chhowalla, M., Robertson, J., Chen, C. W., Silva, S. R. P., Davis, C. A., Amaratunga, G. A. J., and Milne, W. I.: Influence of ion energy and substrate temperature on the optical and electronic properties of tetrahedral amorphous carbon (ta-C) films, J. Appl. Phys., 1, 139-145, https://doi.org/10.1063/1.364000, 1997.

China, S., Mazzoleni, C., Gorkowski, K., Aiken, A. C., and Dubey, M. K.: Morphology and mixing state of individual freshly emitted wildfire carbonaceous particles, Nat. Commun., 4, 2122, https://doi.org/10.1038/ncomms3122, 2013.

Chow, J. C., Watson, J. G., Chen, L.-W. A., Arnott, W. P., Moosmüller, H., and Fung, K.: Equivalence of Elemental Carbon by Thermal/Optical Reflectance and Transmittance with Different Temperature Protocols, Environ. Sci. Technol., 16, 4414-4422, https://doi.org/10.1021/es034936u, 2004.

Commodo, M., de Falco, G., Larciprete, R., D’Anna, A., and Minutolo, P.: On the hydrophilic/hydrophobic character of carbonaceous nanoparticles formed in laminar premixed flames, Exp. Therm. Fl. Sci., 73, 56-63, https://doi.org/10.1016/j.expthermflusci.2015.09.005, 2016.

Cuesta, A., Dhamelincourt, P., Laureyns, J., Martínez-Alonso, A., and Tascón, J. M. D.: Raman microprobe studies on carbon 
materials, Carbon, 8, 1523-1532, https://doi.org/10.1016/00086223(94)90148-1, 1994.

Deboudt, K., Flament, P., Choël, M., Gloter, A., Sobanska, S., and Colliex, C.: Mixing state of aerosols and direct observation of carbonaceous and marine coatings on African dust by individual particle analysis, J. Geophys. Res., D24, 833, https://doi.org/10.1029/2010JD013921, 2010.

Després, V., Huffman, J. A., Burrows, S. M., Hoose, C., Safatov, A., Buryak, G., Fröhlich-Nowoisky, J., Elbert, W., Andreae, M., Pöschl, U., and Jaenicke, R.: Primary biological aerosol particles in the atmosphere. A review, Tellus B, 1, 15598, https://doi.org/10.3402/tellusb.v64i0.15598, 2012.

Dippel, B., Jander, H., and Heintzenberg, J.: NIR FT Raman spectroscopic study of flame soot, Phys. Chem. Chem. Phys., 20, 4707-4712, https://doi.org/10.1039/a904529e, 1999.

EEA: Air Quality in Europe - 2017 Report, EAA report, Copenhagen, 2017.

Ess, M. N., Ferry, D., Kireeva, E. D., Niessner, R., Ouf, F.X., and Ivleva, N. P.: In situ Raman microspectroscopic analysis of soot samples with different organic carbon content. Structural changes during heating, Carbon, 105, 572-585, https://doi.org/10.1016/j.carbon.2016.04.056, 2016.

Fan, X., Wei, S., Zhu, M., Song, J., and Peng, P.: Comprehensive characterization of humic-like substances in smoke PM2.5 emitted from the combustion of biomass materials and fossil fuels, Atmos. Chem. Phys., 16, 13321-13340, https://doi.org/10.5194/acp-16-13321-2016, 2016.

Ferrari, A. C. and Robertson, J.: Interpretation of Raman spectra of disordered and amorphous carbon, Phys. Rev. B, 20, 1409514107, https://doi.org/10.1103/PhysRevB.61.14095, 2000.

Fultz, B. and Howe, J. M.: Transmission electron microscopy and diffractometry of materials, Physics and astronomy online library, Springer, Berlin, 2001.

Gammer, C., Mangler, C., Rentenberger, C., and Karnthaler, H. P.: Quantitative local profile analysis of nanomaterials by electron diffraction, Scripta Materialia, 3, 312-315, https://doi.org/10.1016/j.scriptamat.2010.04.019, 2010.

Graber, E. R. and Rudich, Y.: Atmospheric HULIS: How humiclike are they? A comprehensive and critical review, Atmos. Chem. Phys., 6, 729-753, https://doi.org/10.5194/acp-6-7292006, 2006.

Highwood, E. J. and Kinnersley, R. P.: When smoke gets in our eyes. The multiple impacts of atmospheric black carbon on climate, air quality and health, Environ. Int., 4, 560-566, https://doi.org/10.1016/j.envint.2005.12.003, 2006.

Hitzenberger, R. and Tohno, S.: Comparison of black carbon (BC) aerosols in two urban areas - concentrations and size distributions, Atmos. Environ., 12, 2153-2167, https://doi.org/10.1016/S1352-2310(00)00480-5, 2001.

Hitzenberger, R., Petzold, A., Bauer, H., Ctyroky, P., Pouresmaeil, P., Laskus, L., and Puxbaum, H.: Intercomparison of Thermal and Optical Measurement Methods for Elemental Carbon and Black Carbon at an Urban Location, Environ. Sci. Technol., 20, 6377-6383, https://doi.org/10.1021/es051228v, 2006.

Hoffer, A., Gelencsér, A., Blazsó, M., Guyon, P., Artaxo, P., and Andreae, M. O.: Diel and seasonal variations in the chemical composition of biomass burning aerosol, Atmos. Chem. Phys., 6, 3505-3515, https://doi.org/10.5194/acp-6-3505-2006, 2006.
Ichikawa, Y. and Naito, S.: Chemical Compositions of Primary $\mathrm{PM}_{2.5}$ Derived from Biomass Burning Emissions, Ajae, 11, 7995, https://doi.org/10.5572/ajae.2017.11.2.079, 2017.

IPCC: Clouds and Aerosols. Climate Change 2013: The Physical Science Basis. Contribution of Working Group I to the Fifth Assessment Report of the Intergovernmental Panel on Climate Change, edited by: Stocker, T. F., Qin, D., Plattner, G.-K., Tignor, M., Allen, S. K., Boschung, J., Nauels, A., Xia, Y., Bex, V., and Midgley, P. M., Cambridge University Press, Cambridge, United Kingdom and New York, NY, USA, 2013.

Ivleva, N. P., McKeon, U., Niessner, R., and Pöschl, U.: Raman Microspectroscopic Analysis of Size-Resolved Atmospheric Aerosol Particle Samples Collected with an ELPI. Soot, HumicLike Substances, and Inorganic Compounds, Aerosol Sci. Technol., 7, 655-671, https://doi.org/10.1080/02786820701376391, $2007 \mathrm{a}$.

Ivleva, N. P., Messerer, A., Yang, X., Niessner, R., and Pöschl, U.: Raman Microspectroscopic Analysis of Changes in the Chemical Structure and Reactivity of Soot in a Diesel Exhaust Aftertreatment Model System, Environ. Sci. Technol., 10, 37023707, https://doi.org/10.1021/es0612448, 2007b.

Jankowski, N., Schmidl, C., Marr, I. L., Bauer, H., and Puxbaum, H.: Comparison of methods for the quantification of carbonate carbon in atmospheric $\mathrm{PM}_{10}$ aerosol samples, Atmos. Environ., 34, 8055-8064, https://doi.org/10.1016/j.atmosenv.2008.06.012, 2008.

Jawhari, T., Roid, A., and Casado, J.: Raman spectroscopic characterization of some commercially available carbon black materials, Carbon, 11, 1561-1565, https://doi.org/10.1016/00086223(95)00117-V, 1995.

Kim, J., Bauer, H., Dobovičnik, T., Hitzenberger, R., Lottin, D., Ferry, D., and Petzold, A.: Assessing Optical Properties and Refractive Index of Combustion Aerosol Particles Through Combined Experimental and Modeling Studies, Aerosol Sci. Technol., 5, 340-350, https://doi.org/10.1080/02786826.2015.1020996, 2015.

Knauer, M., Schuster, M. E., Su, D., Schlögl, R., Niessner, R., and Ivleva, N. P.: Soot Structure and Reactivity Analysis by Raman Microspectroscopy, Temperature-Programmed Oxidation, and High-Resolution Transmission Electron Microscopy, J. Phys. Chem. A, 50, 13871-13880, https://doi.org/10.1021/jp905639d, 2009.

Kubelka, P. and Munk, F.: Ein Beitrag zur Optik der Farbanstriche, Zeitschrift für Technische Physik, 12, 593-601, 1931.

Mamakos, A., Khalek, I., Giannelli, R., and Spears, M.: Characterization of Combustion Aerosol Produced by a Mini-CAST and Treated in a Catalytic Stripper, Aerosol Sci. Technol., 8, $927-$ 936, https://doi.org/10.1080/02786826.2013.802762, 2013.

Mayol-Bracero, O. L.: Water-soluble organic compounds in biomass burning aerosols over Amazonia 2. Apportionment of the chemical composition and importance of the polyacidic fraction, J. Geophys. Res., D20, 995, https://doi.org/10.1029/2001JD000522, 2002.

McNeill, V. F.: Atmospheric Aerosols. Clouds, Chemistry, and Climate, Annu. Rev. Chem. Biomol. Eng., 1, 427-444, https://doi.org/10.1146/annurev-chembioeng-060816-101538, 2017.

Mesquita, S. R., van Drooge, B. L., Dall'Osto, M., Grimalt, J. O., Barata, C., Vieira, N., Guimarães, L., and Piña, B.: Toxic 
potential of organic constituents of submicron particulate matter $\left(\mathrm{PM}_{1}\right)$ in an urban road site (Barcelona), Environ. Sci. Pollut. Res., 18, 15406-15415, https://doi.org/10.1007/s11356-0179201-4, 2017.

Moore, R. H., Ziemba, L. D., Dutcher, D., Beyersdorf, A. J., Chan, K., Crumeyrolle, S., Raymond, T. M., Thornhill, K. L., Winstead, E. L., and Anderson, B. E.: Mapping the Operation of the Miniature Combustion Aerosol Standard (MiniCAST) Soot Generator, Aerosol Sci. Technol., 5, 467-479, https://doi.org/10.1080/02786826.2014.890694, 2014.

Moosmüller, H., Arnott, W. P., Rogers, C. F., Chow, J. C., Frazier, C. A., Sherman, L. E., and Dietrich, D. L.: Photoacoustic and filter measurements related to aerosol light absorption during the Northern Front Range Air Quality Study (Colorado 1996/1997), J. Geophys. Res., D21, 28149-28157, https://doi.org/10.1029/98JD02618, 1998.

Müller, K., Spindler, G., Maenhaut, W., Hitzenberger, R., Wieprecht, W., Baltensperger, U., and ten Brink, H.: INTERCOMP2000, a campaign to assess the comparability of methods in use in Europe for measuring aerosol composition, Atmos. Environ., 38, 6459-6466, https://doi.org/10.1016/j.atmosenv.2004.08.031, 2004.

Okada, K. and Hitzenberger, R. M.: Mixing properties of individual submicrometer aerosol particles in Vienna, Atmos. Environ., 32, 5617-5628, https://doi.org/10.1016/S1352-2310(01)00126$1,2001$.

Panteliadis, P., Hafkenscheid, T., Cary, B., Diapouli, E., Fischer, A., Favez, O., Quincey, P., Viana, M., Hitzenberger, R., Vecchi, R., Saraga, D., Sciare, J., Jaffrezo, J. L., John, A., Schwarz, J., Giannoni, M., Novak, J., Karanasiou, A., Fermo, P., and Maenhaut, W.: ECOC comparison exercise with identical thermal protocols after temperature offset correction - instrument diagnostics by in-depth evaluation of operational parameters, Atmos. Meas. Tech., 8, 779-792, https://doi.org/10.5194/amt-8779-2015, 2015.

Park, S. S. and Yu, J.: Chemical and light absorption properties of humic-like substances from biomass burning emissions under controlled combustion experiments, Atmos. Environ., 136, 114122, https://doi.org/10.1016/j.atmosenv.2016.04.022, 2016.

Park, S., Son, S.-C., and Lee, S.: Characterization, sources, and light absorption of fine organic aerosols during summer and winter at an urban site, Atmos. Res., 213, 370-380, https://doi.org/10.1016/j.atmosres.2018.06.017, 2018.

Partanen, A.-I., Landry, J.-S., and Matthews, H. D.: Climate and health implications of future aerosol emission scenarios, Environ. Res. Lett., 13, 024028, https://doi.org/10.1088/17489326/aaa511, 2018.

Petzold, A., Ogren, J. A., Fiebig, M., Laj, P., Li, S.-M., Baltensperger, U., Holzer-Popp, T., Kinne, S., Pappalardo, G., Sugimoto, N., Wehrli, C., Wiedensohler, A., and Zhang, X.-Y.: Recommendations for reporting "black carbon" measurements, Atmos. Chem. Phys., 13, 8365-8379, https://doi.org/10.5194/acp13-8365-2013, 2013.

Pöschl, U.: Atmospheric Aerosols. Composition, Transformation, Climate and Health Effects, Angew. Chem. Int. Ed., 46, 75207540, https://doi.org/10.1002/anie.200501122, 2005.

Pratt, K. A. and Prather, K. A.: Aircraft measurements of vertical profiles of aerosol mixing states, J. Geophys. Res., D11, 3131, https://doi.org/10.1029/2009JD013150, 2010.
Reisinger, P., Wonaschütz, A., Hitzenberger, R., Petzold, A., Bauer, H., Jankowski, N., Puxbaum, H., Chi, X., and Maenhaut, W.: Intercomparison of Measurement Techniques for Black or Elemental Carbon Under Urban Background Conditions in Wintertime. Influence of Biomass Combustion, Environ. Sci. Technol., 3, 884-889, https://doi.org/10.1021/es0715041, 2008.

Robertson, J. and O'Reilly, E. P.: Electronic and atomic structure of amorphous carbon, Phys. Rev. B, 6, 2946-2957, https://doi.org/10.1103/PhysRevB.35.2946, 1987.

Rohr, A. and McDonald, J.: Health effects of carboncontaining particulate matter. Focus on sources and recent research program results, Crit. Rev. Toxicol., 2, 97-137, https://doi.org/10.3109/10408444.2015.1107024, 2015.

Rosen, H. and Novakov, T.: Identification of primary particulate carbon and sulfate species by Raman spectroscopy, Atmos. Environ., 12, 923-927, https://doi.org/10.1016/0004-6981(78)90031$8,1978$.

Sadezky, A., Muckenhuber, H., Grothe, H., Niessner, R., and Pöschl, U.: Raman microspectroscopy of soot and related carbonaceous materials. Spectral analysis and structural information, Carbon, 8, 1731-1742, https://doi.org/10.1016/j.carbon.2005.02.018, 2005.

Schmid, J., Grob, B., Niessner, R., and Ivleva, N. P.: Multiwavelength Raman Microspectroscopy for Rapid Prediction of Soot Oxidation Reactivity, Anal. Chem., 4, 1173-1179, https://doi.org/10.1021/ac102939w, 2011.

Schmidl, C., Bauer, H., Dattler, A., Hitzenberger, R., Weissenboeck, G., Marr, I. L., and Puxbaum, H.: Chemical characterisation of particle emissions from burning leaves, Atmos. Environ., 40, 9070-9079, https://doi.org/10.1016/j.atmosenv.2008.09.010, 2008.

Schwarz, J. P., Gao, R. S., Fahey, D. W., Thomson, D. S., Watts, L. A., Wilson, J. C., Reeves, J. M., Darbeheshti, M., Baumgardner, D. G., Kok, G. L., Chung, S. H., Schulz, M., Hendricks, J., Lauer, A., Kärcher, B., Slowik, J. G., Rosenlof, K. H., Thompson, T. L., Langford, A. O., Loewenstein, M., and Aikin, K. C.: Single-particle measurements of midlatitude black carbon and light-scattering aerosols from the boundary layer to the lower stratosphere, J. Geophys. Res., D16, 2845, https://doi.org/10.1029/2006JD007076, 2006.

Sedlacek, A. J., Onasch, T. B., Nichman, L., Lewis, E. R., Davidovits, P., Freedman, A., and Williams, L.: Formation of refractory black carbon by SP2-induced charring of organic aerosol, Aerosol Sci. Technol., 12, 1345-1350, https://doi.org/10.1080/02786826.2018.1531107, 2018.

Stadelmann, P.: Java Electron Microscopy Software JEMS, available at: https://cime.epfl.ch/ (last access: 7 June 2019), 2004.

Stephens, M., Turner, N., and Sandberg, J.: Particle identification by laser-induced incandescence in a solid-state laser cavity, Appl. Optics, 19, 3726, https://doi.org/10.1364/AO.42.003726, 2003.

Sun, H., Biedermann, L., and Bond, T. C.: Color of brown carbon. A model for ultraviolet and visible light absorption by organic carbon aerosol, Geophys. Res. Lett., 17, 3131, https://doi.org/10.1029/2007GL029797, 2007.

Sun, J., Zhi, G., Hitzenberger, R., Chen, Y., Tian, C., Zhang, Y., Feng, Y., Cheng, M., Zhang, Y., Cai, J., Chen, F., Qiu, Y., Jiang, Z., Li, J., Zhang, G., and Mo, Y.: Emission factors and light absorption properties of brown carbon from household 
coal combustion in China, Atmos. Chem. Phys., 17, 4769-4780, https://doi.org/10.5194/acp-17-4769-2017, 2017.

Sze, S. K., Siddique, N., Sloan, J. J., and Escribano, R.: Raman spectroscopic characterization of carbonaceous aerosols, Atmos. Environ., 3, 561-568, https://doi.org/10.1016/S13522310(00)00325-3, 2001.

Tuinstra, F. and Koenig, J. L.: Raman Spectrum of Graphite, J. Chem. Phys., 3, 1126-1130, https://doi.org/10.1063/1.1674108, 1970.

Venkatachari, P., Zhou, L., Hopke, P. K., Schwab, J. J., Demerjian, K. L., Weimer, S., Hogrefe, O., Felton, D., and Rattigan, O.: An Intercomparison of Measurement Methods for Carbonaceous Aerosol in the Ambient Air in New York City, Aerosol Sci. Technol., 40, 788-795, https://doi.org/10.1080/02786820500380289, 2006.

Wang, Y., Chung, A., and Paulson, S. E.: The effect of metal salts on quantification of elemental and organic carbon in diesel exhaust particles using thermal-optical evolved gas analysis, Atmos. Chem. Phys., 10, 11447-11457, https://doi.org/10.5194/acp-1011447-2010, 2010.

Watson, J. G., Chow, J. C., and Chen, L. W. A.: Summary of Organic and Elemental Carbon/Black Carbon Analysis Methods and Intercomparisons, Aerosol Air Qual. Res., 5, 65-102, 2005.

Wonaschütz, A., Hitzenberger, R., Bauer, H., Pouresmaeil, P., Klatzer, B., Caseiro, A., and Puxbaum, H.: Application of the Integrating Sphere Method to Separate the Contributions of Brown and Black Carbon in Atmospheric Aerosols, Environ. Sci. Technol., 43, 1141-1146, https://doi.org/10.1021/es8008503, 2009.

Ye, Q., Gu, P., Li, H. Z., Robinson, E. S., Lipsky, E., Kaltsonoudis, C., Lee, A. K. Y., Apte, J. S., Robinson, A. L., Sullivan, R. C., Presto, A. A., and Donahue, N. M.: Spatial Variability of Sources and Mixing State of Atmospheric Particles in a Metropolitan Area, Environ. Sci. Technol., 12, 6807-6815, https://doi.org/10.1021/acs.est.8b01011, 2018.
Yttri, K. E., Aas, W., Bjerke, A., Cape, J. N., Cavalli, F., Ceburnis, D., Dye, C., Emblico, L., Facchini, M. C., Forster, C., Hanssen, J. E., Hansson, H. C., Jennings, S. G., Maenhaut, W., Putaud, J. P., and Tørseth, K.: Elemental and organic carbon in $\mathrm{PM}_{10}$ : a one year measurement campaign within the European Monitoring and Evaluation Programme EMEP, Atmos. Chem. Phys., 7, 5711-5725, https://doi.org/10.5194/acp-7-5711-2007, 2007.

Yu, J. Z., Xu, J., and Yang, H.: Charring Characteristics of Atmospheric Organic Particulate Matter in Thermal Analysis, Environ. Sci. Technol., 36, 754-761, https://doi.org/10.1021/es015540q, 2002.

Zhang, G., Bi, X., He, J., Chen, D., Lo Chan, Y., Xie, G., Wang, X., Sheng, G., Fu, J., and Zhou, Z.: Variation of secondary coatings associated with elemental carbon by single particle analysis, Atmos. Environ., 92, 162-170, https://doi.org/10.1016/j.atmosenv.2014.04.018, 2014.

Zhu, Y., Huang, L., Li, J., Ying, Q., Zhang, H., Liu, X., Liao, H., Li, N., Liu, Z., Mao, Y., Fang, H., and Hu, J.: Sources of particulate matter in China. Insights from source apportionment studies published in 1987-2017, Environ. Int., 115, 343-357, https://doi.org/10.1016/j.envint.2018.03.037, 2018.

Zickler, G. A., Smarsly, B., Gierlinger, N., Peterlik, H., and Paris, O.: A reconsideration of the relationship between the crystallite size $L_{\mathrm{a}}$ of carbons determined by X-ray diffraction and Raman spectroscopy, Carbon, 44, 3239-3246, https://doi.org/10.1016/j.carbon.2006.06.029, 2006. 